\title{
New metrics for measuring supply chain reconfigurability
}

\author{
Slim Zidi ${ }^{1,2}$ [D $\cdot$ Nadia Hamani ${ }^{2} \odot \cdot$ Lyes Kermad $^{1}$ \\ Received: 24 January 2021 / Accepted: 29 May 2021 / Published online: 23 June 2021 \\ (c) The Author(s), under exclusive licence to Springer Science+Business Media, LLC, part of Springer Nature 2021
}

\begin{abstract}
The COVID 19 pandemic, fluctuating demand, market uncertainty and the emergence of new technologies explain the need for a more flexible and agile supply chain. In fact, several important factors should be taken into account in the process of building an adaptive and reconfigurable supply chain. Reconfigurability is used to measure quantitatively the capability of supply chain to change easily their structure and functions. The aim of this work is to evaluate the level of reconfigurability of a supply chain. Quantitative measures of six indicators that characterize reconfigurability are presented in this paper. Then, an index of reconfigurability in supply chain is developed based on The Multi-Attribute Utility Theory in order to choose the most reconfigurable configuration. An illustrative example is also given. From the discussion, it is deduced that the characteristics of the reconfigurable supply chain impacts positively on the degree of reconfigurability.
\end{abstract}

Keywords Reconfigurable supply chain (RSC) $\cdot$ Reconfigurability characteristics $\cdot$ Reconfigurability assessment $\cdot$ Multiattribute utility theory (MAUT)

\section{Introduction}

Market instability and uncertainty affect supply chain performance and reveal its inability to deal with these disruptions. Recently, companies have started reconfiguring their supply chain in response to the new markets trends (Zidi et al., 2019, 2021). Ensuring supply chain flexibility, agility, resilience and viability requires the development of a supply chain called Reconfigurable Supply Chain (RSC) that is able to cope with the various changes. The latter is able to cope with the various market changes. Therefore, it is important to consider uncertainty in the decision making process to achieve a successful reconfiguration strategy (Bensoussia et al., 2021). RSC is defined as a flexible chain capable of changing its structure with the minimum

Slim Zidi

slim.zidi02@etud.univ-paris8.fr

Nadia Hamani

nadia.hamani@u-picardie.fr

Lyes Kermad

1.kermad@iut.univ-paris8.fr

1 University of Paris 8, 140 Rue de la Nouvelle France, Montreuil, France

2 University of Picardie Jules Verne, 48 Rue d'Ostende, Saint-Quentin, France of resources (Chandra \& Grabis, 2016). Dolgui et al. (2020) considered that the supply chain reconfigurability is a central perspective that offers a variety of features in supply chain adaptation research. (Dolgui et al., 2018; Ivanov \& Dolgui, 2020; Ivanov et al., 2017) highlighted the crucial role of reconfiguration to mitigate the ripple effect and to deal with supply chain disruptions. Besides, (Dolgui \& Ivanov, 2020; Dolgui et al., 2020) showed that RSC has an important role in ensuring competitiveness in the markets.

In the literature, reconfigurability was usually treated as a form of changeability that can be applied at the equipment level, production system level and assembly system level to change system capabilities and functionality rapidly and cost-effectively (ElMaraghy, 2005; Koren \& Shpitalni, 2010; Mehrabi et al., 2000). This modification can be a quick and cost-effective addition, removal and/or reorganization of system components and functions. In other words, it represents the addition or removal of new products or resources to achieve the desired configurations. The concept of reconfiguration has been extended, in recent years, to include changes in supply chain levels (Dolgui et al., 2020). RSC is a network designed in a cost-efficient, responsive, sustainable and resilient manner. This network can change rapidly its structure (Dolgui et al., 2020). RSC can be considered as a concept required for farming supply chain viability which 
is the ability to survive in a changing environment by redesigning the supply chain structures (Ivanov, 2020).

Few researchers have addressed the problem of reconfigurability assessment based on the six reconfiguration characteristics (modularity, integrability, convertibility, diagnosability and scalability). Several authors pointed out that these characteristics reduce reconfiguration efforts in production systems (Koren \& Shpitalni, 2010; Napoleone et al., 2018a), which justifies the interest in these characteristics as metrics for reconfigurability measurement. Reconfigurability can be also considered as an asset for industries to meet the changing market requirements. Indeed, a system with a high degree of reconfigurability is able to increase its production rate and product range with minimal time and cost. The reconfiguration concept can be applied on the below-mentioned several levels (Wiendahl \& Heger, 2004):

- The network level which is the highest level and integrating all the sites in relation with the manufacturing company;

- The factory level covering the building and infrastructure of the production plant;

- The segment level which covers all production activities and those related to the preparation of the products for shipping;

- The system level containing interconnected cells ensuring the production of a variation of products or product families;

- The cell level which is a subsystem including groups of work stations and material handling systems for product finishing;

- The workstation level, which is the lowest level integrating workstations and machines, allow adding some functions to specific pieces.

Napoleone et al. (2018b) believed that the factory and segment levels as well as the system and cell levels can be associated. Reconfigurability can refers to the four levels:

- The network level and the workstation level which have the same definitions proposed by (Wiendahl \& Heger, 2004),

- The system level is defined as a set of interconnected subsystems composed of groups of workstations and material handling systems used for the production of a variation of products or product families. In this level, system configurations can be applied at the cell, line or production department levels.

- The plant level, which refers to a production site composed of production and/or assembly systems that can be considered as a node of a production network or supply chain.
- The workstation level which contains operators and machines performing technological operations.

(Andersen et al., 2015) showed that there is no research work dealing with the network/supply chain level. As indicated by (Wang et al., 2018), supply chain network is composed of nodes that represent multi-functional firms in the supply chain and connect arcs. It is important to focus on networks and how they can be better coordinated, monitored and assessed for risk, so that they are flexible (Palmer et al., 2018). Wang et al., (2016a, 2016b) defined three type of supply chain network structure:

- Starlike structure which means that "several branches evolve from a single node to different parts of the network";

- Tier-based network system which includes structures with several supply chains with common source nodes (suppliers) and destination nodes (customers);

- Supply chains, having interdependent relations, differ in their nature.

In this article, we are interested in the second type of structure and we consider that the supply chain is a set of nodes and connections, as defined by (Wang et al., 2018).

The implementation of a reconfigurable manufacturing system, the reduction of time for new products, the increase of product varieties and the rapid adaptation to market changes require the consideration of supply chain in the reconfiguration process. (Chaube et al., 2012) considered that the lack of supply chain work is one of the problems in implementing a reconfigurable manufacturing system. In an uncertain and changeable environment, the reconfigurability assessment remains important in the evaluation of supply chain performance. Wei et al. (2007) proved that supply chain reconfigurability affects considerably the supply chain performance. In order to evaluate the degree of reconfigurability, either at the supply chain or at the manufacturing systems level, many works were proposed based on different criteria which can be classified according to the level of application and the evaluation criteria. Thus, the present work proposes an index of reconfigurability to evaluate the ability of supply chain configuration to deal with market changes. The RSC characteristics are considered as indicators to judge the degree of reconfigurability.

The rest of the article is organized as follows, Sect. 2 reviews the literature about reconfigurability assessment. Section 3 presents the proposed measurement of RSC characteristics and the reconfigurability index using MAUT, while Sect. 4 presents an illustrative example of the characteristics measurement and reconfigurability assessment. Section 5 discusses the obtained results. Section 6 highlights the managerial implications and the benefits of the proposed 
approach for decision makers. Finally, Sect. 7 summarizes the conclusions and recommendations for further works.

\section{Literature review}

The supply chain can be considered as a system composed of components and connections. Zhang and Wang (2016) considered that the considerable variation in the structure of the enterprise system and the high volatility of demand and market sharing provoke the problem of choosing the best change for a new system. This changeability is mainly based on 6 aspects defined as FCBPSS framework (Zhang $\&$ Wang, 2016; Zhang et al., 2005): (1) function referring to "the role a system plays"; (2) context of "the condition and the environment under which a function is played by a system; (3) behavior that refers to the input (stimuli)- output (response); (4) principle indicating "the government of the behavior"; (5) state showing "the property or characteristics of a system" and (6) structure corresponding "to a set of connected components".

In the supply chain reconfiguration, the previouslymentioned aspects allow changing the configuration of the supply chain and choose the best one that can be adjusted to the new changes.

The configuration is a set of modules and their connections. Its representation can be divided into module representation and connection representation (Bi et al., 2010).
Indeed, the implementation of a reconfigurable supply chain means the possibility of choosing a configuration among the best ones to be adapted to the new changes. In fact, the modification in the configuration of the supply chain increases its resilience. According to Wang et al. (2020), resilience can be achieved by changing many aspects such as topology, state, context, etc. In this paper, we consider that the supply chain can be reconfigured by changing its structure or its functions.

Several works were carried out to evaluate the reconfigurability of Reconfigurable Manufacturing Systems (RMS). However, the proposed works on assessment relying on reconfigurability characteristics is very poorly developed, not to mention the evaluation of reconfigurability in supply chains. In this respect, some authors showed that the implementation of monitoring and evaluation systems is necessary and useful to determine the degree of the system reconfigurability. To describe the existing works dealing with the evaluation of reconfigurability in RMS and CLRs, we first present a state-of-the-art on quantitative and qualitative approaches that have suggested measures to assess the degree of reconfigurability. These approaches are summarized in Table 1.

Various performance indicators, including those that measure costs, reconfiguration times, reliability, productivity, etc., were introduced to assess the degree of reconfigurability. (Bi et al., 2003) proposed an approach to design a reconfigurable robotic system. The degree of
Table 1 Classification of the proposed approaches in reconfigurability assessment

\begin{tabular}{|c|c|c|c|c|c|c|}
\hline & Quantitative & Qualitative & Workstation & Cell & System & $\begin{array}{l}\text { Network/ } \\
\text { Supply } \\
\text { chain }\end{array}$ \\
\hline Bi et al., (2003) & $\checkmark$ & & & & $\checkmark$ & \\
\hline Ma et al., (2007) & & $\checkmark$ & & & & $\checkmark$ \\
\hline Gumasta et al., (2011) & $\checkmark$ & & $\checkmark$ & & $\checkmark$ & \\
\hline Goyal et al., (2012) & $\checkmark$ & & $\checkmark$ & & & \\
\hline Farid (2014) & $\checkmark$ & & $\checkmark$ & & & \\
\hline Mittal and Jain (2014) & $\checkmark$ & & $\checkmark$ & & & \\
\hline Gupta et al., (2015) & $\checkmark$ & & $\checkmark$ & $\checkmark$ & $\checkmark$ & \\
\hline Goyal and Jain (2015) & $\checkmark$ & & & $\checkmark$ & & \\
\hline Delorme et al., (2016) & $\checkmark$ & & & $\checkmark$ & & \\
\hline Dahane and Benyoucef, (2016) & $\checkmark$ & & $\checkmark$ & & & \\
\hline Biswas (2017) & & $\checkmark$ & & & & $\checkmark$ \\
\hline Wang et al., (2016a, 2016b) & $\checkmark$ & & $\checkmark$ & $\checkmark$ & $\checkmark$ & \\
\hline (Napoleone et al., , 2018a, 2018b) & & $\checkmark$ & $\checkmark$ & $\checkmark$ & $\checkmark$ & \\
\hline Maganha et al., (2018) & & $\checkmark$ & $\checkmark$ & $\checkmark$ & $\checkmark$ & \\
\hline Maganha et al., (2019a, 2019b) & $\checkmark$ & & & & $\checkmark$ & \\
\hline Biswas et al., (2019) & & $\checkmark$ & & & & $\checkmark$ \\
\hline Beauville dit Eynaud et al., (2019) & & $\checkmark$ & & & $\checkmark$ & \\
\hline Rösiö et al., (2019) & & $\checkmark$ & $\checkmark$ & $\checkmark$ & $\checkmark$ & \\
\hline Prasad and Jayswal (2019) & $\checkmark$ & & & & $\checkmark$ & \\
\hline
\end{tabular}


reconfigurability was determined from the sufficiency of the number of robotic configurations generated from the reconfigurable system for a specific task. To evaluate the degree of reconfigurability, Bin Ma et al. (2007) presented a fuzzy logic model to assess the supply chain reconfigurability based on four qualitative criteria (the ability to change the supply chain for existing product, the ability to change the supply chain for a new product, the time to change for an existing product and the time to change for new product). To choose the best configuration, Gumasta et al. (2011) introduced an index of reconfigurability in RMS based on four characteristics: modularity, scalability, convertibility and diagnosability. Measurements of the latter were collected through a literature review. The authors adopted these measures to propose a reconfigurability index that takes into consideration the previously-mentioned characteristics. In the same context, Farid (2014) presented a reconfigurability evaluation model in RMS based on modularity, integrability, convertibility and customization through two metrics: the potential for reconfigurability and the ease of reconfigurability. This model was applied to an automatic and intelligent production system composed of three levels: production level, execution level and decision-making level. The author showed that reconfigurability includes only five characteristics, namely the four above-stated ones and diagnosability. The latter was not considered in the suggested model because it does not impact its structure, but only its behavior. In the same context, an index of reconfigurability was developed by (Wang et al., 2016a, 2016b) based on the six reconfigurability characteristics defined by (Koren et al., 1999). For each characteristic, a quantitative model was proposed to construct an RMS evaluation index system. In an automobile case supply chain, Biswas et al. (2019) presented a comprehensive relative reconfigurability index by utilizing the Total Interpretive Structural Modeling (TISM) and an integrated assessment methodology based on Delphi technique and the additive weighting method.

In contrast, other RMS evaluation using other measures than reconfiguration characteristics were developed. Goyal et al. (2012) introduced three indicators for machine selection based on the cost of a feasible alternative machine configuration, the reconfigurability and operational capability offered by the machines. To select the optimal configuration in RMS, Mittal and Jain (2014) proposed a performance measurements enabling a responsive reconfigurable manufacturing system relying on cost, reliability, utilization and quality. In the same context, Gupta et al. (2015) suggested a set of indicators such as: convertibility, scalability, productivity and cost to select the best configuration as well as the type of machine and its specifications. As part of the design of the RMS, Goyal and Jain, (2015) presented a set of performance indicators such as cost, machine utilization, configuration convertibility and operational capacity to optimize the design of reconfigurable production lines. Furthermore, (Delorme et al. (2016) developed a model based on the GRASP (Greedy Randomized Adaptive Search procedure) framework to study the line balancing problem for a reconfigurable transfer line. The model is based on two criteria including total cost and cycle time. Dahane and Benyoucef (2016) proposed a multi-objective approach for a reconfigurable manufacturing system design for a machine selection problem. The selection process relies on the minimization of total cost, including machine usage cost and machine maintenance cost, and the maximization of the reconfigurability index. Prasad and Jayswal (2019) developed a methodology which facilitates the concept of reconfiguration in the manufacturing system. This methodology includes the calculation of similarity matrix, the formation of part family and the selection of part family based on three criteria, namely reconfiguration effort, under-utilization cost and floor space cost (Biswas et al., 2019). Apart from reconfigurability, quantitative measures were proposed by several authors to evaluate supply chain performance in a changing environment. For instance, Raj et al. (2015) introduced a quantitative measurement of supply chain resilience, in terms of recovery time. The developed model allows measuring the degree of supply chain resilience for different sources of disruptions. In the context of enterprise information system, J. W. Wang et al. (2010) presented a resilient measurement based on the recovery ability of the system. This measure was addressed for the resource reallocation problem. The authors considered reconfiguration and resource reallocation for the measurement of service system resilience.

To better understand the enablers that facilitate the reconfigurability of supply chains, Biswas (2017) conducted an empirical study to identify the enablers of each reconfigurability characteristic in order to facilitate reconfiguration in the supply chain. Napoleone et al., (2018a, 2018b) analyzed RMS characteristics after having summarized the articles dealing with reconfigurability and its characteristics. They revealed the importance of the six characteristics affecting the reconfiguration effort through reconfiguration time and cost as well as the ramp-up time. These characteristics can be classified according to their positioning within the system lifecycle. The first level, including modularity, integrability and diagnosability, is that of configuration level. These three characteristics affects the ability of the system to modify its configuration. This ability corresponds to the reconfiguration level through diagnosability, convertibility and scalability. Finally, for customization, it depends on the market and demand. Then, the authors determined the interactions between these characteristics by defining the influencing factors and influenced elements for each characteristic. Maganha et al. (2018) realized an empirical study on reconfigurability in RMS in order to test and validate 
its characteristics through questionnaire surveys carried out by Portuguese companies. This study showed that reconfigurability has five characteristics instead of six: modularity, integrability, diagnosability, customization and adaptability which is a merger between convertibility and scalability. In order to measure these five characteristics, Maganha et al., (2019a, 2019b) suggested a reconfigurability index that considers the relation between them. This index allows, firstly, a better understanding of the key factors of reconfigurability. Secondly, a focus was put on the characteristics that require more attention to improve the reconfigurability of RMS. To investigate the difference in the implementation of reconfigurability between the different production strategies (i.e. make-to-order, make-to-stock, assembly-to-order and Design-to-order), Maganha et al., (2019a, 2019b) proposed a questionnaire survey for reconfigurability measurement. This measure provides an understanding of the reconfigurability requirements for each production strategy. According to (Rösiö et al., 2019), the introduced quantitative measures are difficult and not obvious to practitioners. They also require an expertise in the RMS field. In this work, the authors used questionnaire survey to determine the measurement criteria for each characteristic. Beauville dit Eynaud (2019) realized an empirical survey in order to study reconfigurability within an automotive industry. This work highlighted the reconfigurability requirements and weighted the six key characteristics of reconfigurability.

Few approaches considered reconfiguration characteristics: Modularity (M), Convertibility (Co), Integrability (I), Diagnosability (D), Scalability (S) and Customization $(\mathrm{Cu})$ as indicators to assess reconfigurability, as shown in Table 2. The quantitative measures, proposed by (Farid, 2014; Gumasta et al., 2011; Maganha et al., 2019a, 2019b; Wang et al., 2016a, 2016b), include different levels of reconfigurability such as system level, machine level, etc. These measures improved the choice of the best configuration by integrating the different aspects that can affect RMS (system, cell, workstation). However, Wang et al., (2016a, 2016b) is the only work that took into account all the characteristics to measure reconfigurability and help decision-makers choose the optimal configuration. Maganha et al., (2019a, 2019b) proposed a reconfigurability index to consider the relations between the five characteristics after merging convertibility and scalability.

Some authors showed that these quantitative measures are complicated to understand and require expertise in RMS field. The introduced qualitative approaches that address the

Table 2 Criteria used for reconfigurability assessment

\begin{tabular}{|c|c|c|c|c|c|c|c|}
\hline \multirow[t]{2}{*}{ References } & \multicolumn{6}{|c|}{$\begin{array}{l}\text { Reconfigurability character- } \\
\text { istics }\end{array}$} & \multirow[t]{2}{*}{ Other indicators } \\
\hline & M & Co & I & $\mathrm{D}$ & $\mathrm{S}$ & $\mathrm{Cu}$ & \\
\hline Bi et al., (2003) & & & & & & & $\begin{array}{l}\text { (The sufficiency of number of robotic configurations generated from the } \\
\text { reconfigurable system for a specific task) }\end{array}$ \\
\hline Ma et al., (2007) & & & & & & & $\begin{array}{l}\text { (Ability to change supply chain for existing and new product, time to change } \\
\text { for existing and new product) }\end{array}$ \\
\hline Gumasta et al., (2011) & $\checkmark$ & $\checkmark$ & & $\checkmark$ & $\checkmark$ & & \\
\hline Goyal et al., (2012) & & & & & & & (Cost, operational capability, machine reconfigurability) \\
\hline Farid (2014) & $\checkmark$ & $\checkmark$ & $\checkmark$ & & & $\checkmark$ & \\
\hline Mittal and Jain (2014) & & & & & & & (Cost, reliability, utilization, quality) \\
\hline Gupta et al., (2015) & & $\checkmark$ & & & $\checkmark$ & & (Productivity, cost) \\
\hline Goyal and Jain (2015) & & $\checkmark$ & & & & & (Cost, operational capability, machine utilization) \\
\hline Delorme et al., (2016) & & & & & & & (Total cost, cycle time) \\
\hline Dahane and Benyoucef (2016) & & & & & & & (Total cost, reconfigurability index) \\
\hline Biswas (2017) & $\checkmark$ & $\checkmark$ & $\checkmark$ & $\checkmark$ & & $\checkmark$ & \\
\hline Wang et al., (2016a, 2016b) & $\checkmark$ & $\checkmark$ & $\checkmark$ & $\checkmark$ & $\checkmark$ & $\checkmark$ & \\
\hline Napoleone et al., (2018a, 2018b) & $\checkmark$ & $\checkmark$ & $\checkmark$ & $\checkmark$ & $\checkmark$ & $\checkmark$ & \\
\hline Maganha et al., (2018) & $\checkmark$ & $\checkmark$ & $\checkmark$ & $\checkmark$ & $\checkmark$ & $\checkmark$ & $\begin{array}{l}\text { (Convertibility and scalability are merged into a single characteristic called } \\
\text { adaptability) }\end{array}$ \\
\hline Maganha et al., (2019a, 2019b) & $\checkmark$ & $\checkmark$ & $\checkmark$ & $\checkmark$ & $\checkmark$ & $\checkmark$ & \\
\hline Biswas et al., (2019) & $\checkmark$ & $\checkmark$ & $\checkmark$ & $\checkmark$ & & $\checkmark$ & \\
\hline Beauville dit Eynaud et al., (2019) & $\checkmark$ & $\checkmark$ & $\checkmark$ & $\checkmark$ & $\checkmark$ & $\checkmark$ & \\
\hline Rösiö et al., (2019) & $\checkmark$ & $\checkmark$ & $\checkmark$ & $\checkmark$ & $\checkmark$ & $\checkmark$ & \\
\hline Prasad and Jayswal (2019) & & & & & & & (Reconfiguration effort, under-utilization cost, floor space cost) \\
\hline
\end{tabular}


characteristics of reconfigurability identified the key success factors for each of them. The results obtained in these studies depend on the production strategies and the production levels. A better understanding of the success factors of reconfigurability was achieved through these studies, in particular by defining the influencing and influenced elements for each characteristic. Taking these relationships into account is important in future work in order to improve reconfigurability measurements. Although these approaches are effective in assessing reconfigurability in production systems, they do not consider the supply chain level. Therefore, our objective is to propose a model for assessing reconfigurability in supply chains based on this finding.

\section{Proposed approach}

Before implementing the proposed reconfiguration, it is necessary to assess its degree of reconfigurability. The reconfiguration characteristics was used as an indicator for this assessment. This choice is justified by the ability of this characteristics to evaluate several factors that may lead to a successful reconfiguration. Indeed, our approach consists in assessing the reconfiguration characteristics according to a different factor, as shown in Fig. 1. These measurements allowed evaluating the degree of reconfigurability of each configurations. The choice of the best configuration requires the aggregation of the characteristics measurement into a single measure called the reconfigurability index. Therefore, we applied a decision making method based on the MAUT technique. Multi-attribute decision making consists in selecting the best configuration alternative. This method has several advantages such as the consideration of uncertainty and the incorporation of preference (Velasquez \& Hester, 2013).

\section{The proposed measurements of the RSCs characteristics}

\section{Measuring modularity in RSCs}

Modularity in RSCs refers to the degree to which all products, processes and resource entities at all levels of enterprises of supply network are modular (Kelepouris et al., 2006). This characteristic includes three enablers, namely network structure design, responsiveness and total cycle time. It is a fundamental element for the optimization of the supply chain, which allows the quick respond to the demands (Biswas, 2017). (Ezzat et al., 2020) consider modularity as an effective method to better manage product and service variation. Comparing with RMS, modularity was measured through granularity and number of interfaces. Indeed, the level of granularity refers to the size and the detail of the system elements after system decomposition. Interfaces can be between elements of the same module or between modules. The more the interactions between elements of the same module increase, the more the modularity augments. Besides, the more the interactions between modules rise, the more the modularity decreases. Thus, we adopted the number of modules and the number of interfaces to measure the degree of modularity in RSCs by determining the numbers of intra-modules interactions and comparing them with those of inter-modules. The module having the highest number of inputs is that which takes the longest time to work. This indicates that this module will impact the supply chain lead-time which will increase more and more. Thus, the decrease in the number of outputs will reduce the total time of this module and, consequently, the lead time of
Fig. 1 The measurement parameters of the reconfigurability characteristics

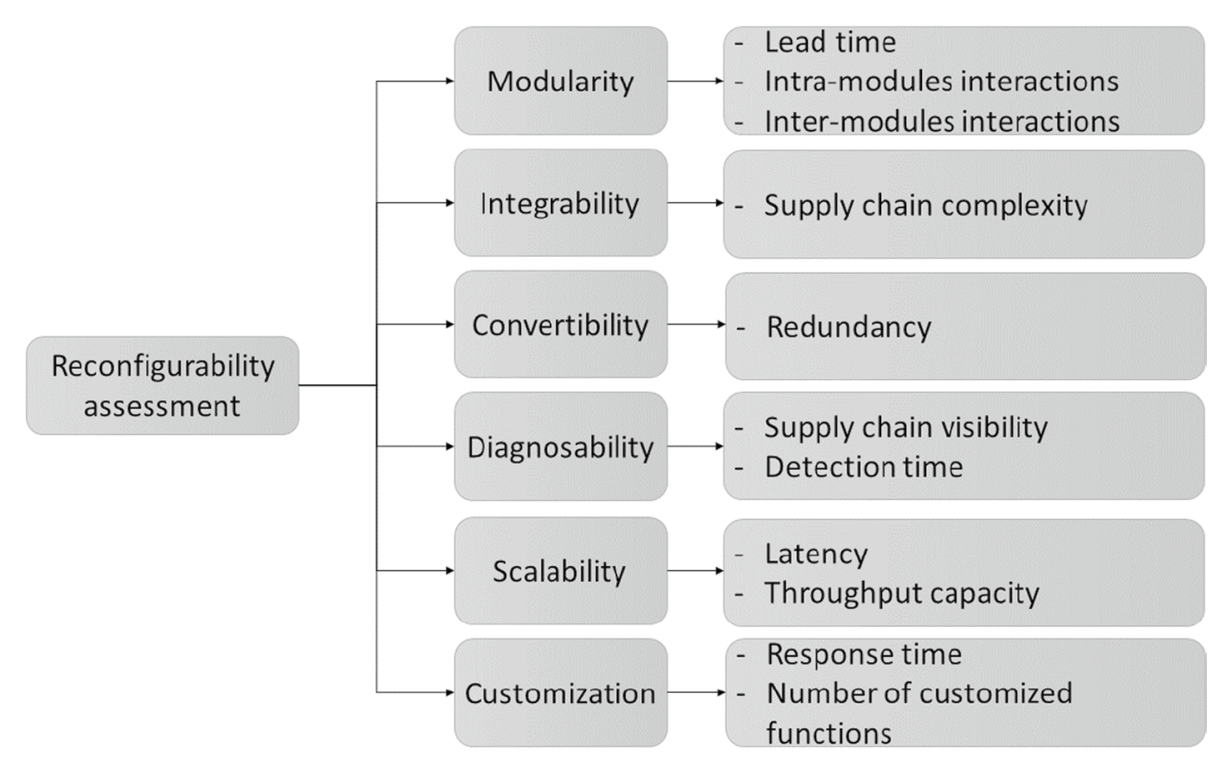


the supply chain. The degree of modularity depends on both the type of interaction (inbound or outbound) of each module and the degree of independence. Hence, it is necessary to take into account the degree of the module influence in the measurement of modularity.

$M$ indicates the degree of modularity comprised between 0 and 1 . Besides, a value of $M$ closer to 1 indicates an important modularity. Ia denotes the degree of intra-relations of each module. It allows understanding the degree of interaction between the elements of each module. When the number of interrelations increases, an important modularity, closer to 1 , is obtained. Ie denotes the degree of inter-module which is the ratio between the number of interactions between modules noted $E_{i}$ and the total of interactions between modules $T E_{i}$ multiplied by the weight assigned for each module $P I_{i}$. Ia is the degree of intra-modules which is the ratio between the number of interactions within the same module noted $A_{i}$ and the total of interactions within the same module noted $T A_{i}$. In supply chain, it is necessary to distinguish between incoming and outgoing flows. Indeed, incoming flows affects considerably the lead-time because a module can only execute the activities after receiving these flows, which will influence the degree of modularity having a direct impact on lead-time. In addition, the outgoing flows have less impact on modularity because the module can be operated without waiting for the outgoing flows to be delivered. This degree is measured by $D I_{i}$ which denotes the degree of influence of each module $i$. $D I i$ is the difference between the sum of the outgoing flows of module $i$, i.e. the sum of the rows corresponding to module $i$ noted $D i$, and the sum of the incoming flows, i.e. the sum of the columns related to module $i$ noted $R i$. Indeed, to make all the degrees of influence $D i$ positive, we added, to each value of $D I i$, the minimum value of the absolute values of DIi noted $X$.

$M=\frac{I a+(1-I e)}{2}$

$I a=\frac{1}{N M} \sum_{i \in N M} \frac{A_{i}}{T A_{i}}$

$I e=\frac{1}{N M} \sum_{i \in N M} \frac{E_{i}}{T E_{i}} \times P I_{i}$

$P I_{i}=\frac{\left(D I_{i}+X\right)}{\sum_{i \in N M}\left(D I_{i}+X\right)}$

$X=\operatorname{Min}\left(\left|D I_{1}\right|,\left|D I_{2}\right|, \ldots,\left|D I_{N M}\right|\right)$

\section{Measuring of integrability in RSCs}

The integrability is defined as the ability with which all enterprises within the supply network and their processes and resources may be readily integrated and future process and resources introduced (Kelepouris et al., 2006). The integration of new products, processes and supply chain stakeholders depends on the supply chain degree of complexity, which makes the supply chain is a complex system. (Hamta et al., 2018) mentioned that there are two types of system complexity: static or structural complexity that deals with the configuration and structure of the system components, and dynamic complexity that addresses the behavior of the system.

The integration of a new actor, a new process or a new product requires additional cost and time. In fact, we integrated these two parameters which depend on the complexity of the supply chain. For integrability, the time and cost of reconfiguration are inversely proportional to the degree of integrability.

$I$ represents the degree of customization of the RSCs ranging from 0 to 1 . A value of $I$ closer to 1 indicates a high integrability degree. This characteristic was measured, in the performed experiment, based on the degree of complexity of the supply chain which depends both on the number of nodes and the number of connections between them. The degree of supply chain complexity, noted $F C$, is the ratio between the total number of connections $T N C$ and the total number of nodes $T N N$. This degree increases if the supply chain has a high number of nodes and connections. The implementation of a modular supply chain ensures independence between the elements of the supply chain, which allows reducing the number of flows between nodes. In addition, integrability is influenced by the reconfiguration cost $\mathrm{Cr}$ and reconfiguration time $T r$ which are successively compared with the Total cost of ownership TCO and total cycle time TCT of the supply chain.

$I=1-\left(F C \times \frac{\left(\frac{T r}{T C T}+\frac{C r}{T C O}\right)}{2}\right)$

$F C=\frac{T N C}{T N N}$

\section{Measuring of convertibility in RSCs}

The convertibility is defined by the ability of the product, process and resource entities within the enterprises of the supply network to quickly changeover between the existing products and adapt the company to future products (Kelepouris et al., 2006). According to (Sheffi and Rice Jr, 2005), supply chain convertibility is the ability to respond quickly to a disruption 
in one of the supply chain entities and adapt to the market changes. It can be evaluated by a key factor which is the redundancy of entities. Indeed, a supply chain with redundant entities has a greater degree of convertibility. While having redundant production lines is expensive, having multiple capabilities, at each plant location, makes the supply chain more flexible. To measure convertibility, we were inspired by the convertibility assessment in RMS proposed by (Chinnathai et al., 2017) who defined system convertibility as an average of equipment convertibility and layout convertibility. Thus, we defined the convertibility of a supply chain as an average of the structural convertibility and the functional convertibility. According to (Maler-Speredelozzi et al., 2003), structural convertibility indicates all the entities that compose the supply chain (nodes, routing connections, etc.). It allows measuring the redundancy rate of the entities within the supply chain. This rate affects the degree of convertibility.

Co indicates the degree of convertibility ranging from 0 to 1 . This degree is composed of two dimensions: $C_{s}$, which indicates structural convertibility, and $C_{f}$ representing the functional convertibility. The structural convertibility depends on the redundancy rate of the nodes and the connections noted $N R$ and $C R$, respectively. $N R N$ refers to the number of redundant nodes and $N R C$ denotes the number of redundant connections. Functional convertibility depends on a convertibility index of activities, noted $L_{a}$ and, a convertibility index of resources noted $L_{r}$. The first index describes the interruption of an activity when converting another activity. For example, a conversion at the purchasing activity can cause a delay at the production activity level. The value of $L_{a}$ depends on the ratio of the total of $n a_{j k} \in N a_{j k}$ which takes 1 , if the activity $j$ can be interrupted when converting activity $k$. Otherwise, it takes 0 . The value of $N_{a}$ corresponds to the number of the total activities in supply chain. Indeed, increasing this ratio means that the convertibility index of the activities decreases and vice versa. The second index measures the redundancy of resources for each activity which depends on the sum of the ratio between $N_{r k}^{R}$ which designates the number of redundant resources associated to the activity $k$. $N_{r k}$ denoting the number of the total resources associated to the activity $k$.

$$
\begin{aligned}
& C o=\frac{C s+C f}{2} \\
& C s=\frac{N R+C R}{2} \\
& N R=\frac{N R N}{T N N} \\
& C R=\frac{N R C}{T N C}
\end{aligned}
$$

$C f=\frac{L a+L r}{2}$

$L a=1-\frac{\frac{\sum_{J \in N A} \sum_{K \in N A} N a_{j k}}{N a-1}}{N a}$

$L r=1-\sum_{k \in N A} \frac{N_{r k}^{R}}{N_{r k}}$

\section{Measuring of diagnosability in RSCs}

The diagnosability is defined as the ability to quickly identify the sources of problems which hamper supply network effectiveness and efficiency (Kelepouris et al., 2006). According to (Biswas, 2017), this characteristic is linked to the three essential enablers (flow visibility, data reliability and resilience) which are directly linked to the flow of information circulating in the supply chain, which must be both reliable and shared, in addition to the degree of adaptability of the supply chain with various changes/mutations and failures that may affect it.

Identifying the failure causes throughout the supply chain requires good visibility of all its components and its physical and information flows. To measure the diagnosability, we focus, in this work, on three factors, namely a factor related to the diagnostic tools in the chain, which makes it possible to measure the availability of the diagnostic tools. The second factor consists in measuring the failure detection time in the supply chain. This factor, called the detection time factor in the supply chain, was used, in the performed experiments, to calculate the ratio of the detection time and the total cycle time of the supply chain. A high detection time involves a decrease in diagnosability degree. The third factor is related to the visibility of the supply chain, which can be measured by the quantity and quality of the information circulated between the different supply chain stakeholders.

$D$ represents the degree of the RSCs diagnosability ranging from 0 to 1 . Moreover, a value of close $D$ to 1 indicates a high value of the latter. It depends on two essential factors that increase its value. $F T_{e}$ designates the factor of the detection time in the RSCs, which is the ratio of the failure detection time on the echelon $e$ noted $T_{e}^{d}$ and the total cycle time of the echelon $e$ noted $T_{e}^{c} . F V$ denoted the factor of visibility. For the visibility, known as $V_{I}$, we adopted the formula proposed by (Caridi et al., 2010). This formula is based on the quantitative and qualitative measurement of the information flow, as demonstrated in Table 3. The judgments rely on qualitative scales with two response levels of response.

$V_{e}^{Q n}$ denotes the visibility of the quantity of information related to the echelon $e$ measured using the judgment on the quantity related to internal and external flows for echelon 
$e$ denoted respectively $J_{e, q, I F}$ and $J_{e, q, E F} . V_{e}^{Q l}$ refers to the visibility of the quality of information for the echelon $e$ measured using the judgement on the precision in of the internal and external flows denoted respectively $J_{e, p, I F}$ and $J_{e, p, E F}$, and the judgement on the freshness in the internal and external flows denoted $J_{e, q, I F}$ and $J_{e, q, E F}$, respectively. This measurement affects directly the degree of diagnosability.

$D=\frac{1}{N E} \sum_{e \in N E} F T e \times F V$

$F T_{e}=\frac{1}{N E} \sum_{e \in N E} \frac{T_{e}^{d}}{T e^{c}}$

$V_{e}^{Q n}=\frac{\sqrt[2]{J_{e, q, I F} \times J_{e, q, E F}}}{2}$

$V_{e}^{Q l}=\frac{\sqrt[2]{\sqrt[2]{J_{e, p, I F} \times J_{e, p, E F}} \times \sqrt[2]{J_{e, f, I F} \times J_{e, f, E F}}}}{2}$

$V I S_{e}=\sqrt{V_{e}^{Q n} \times V_{e}^{Q l}}$

$F V=\sum_{e \in N E} V I S_{e}$

\section{Measuring scalability in RSCs}

Durowoju et al. (2011) considered that the impact of scalability on supply chain performance can be modeled as a function of lead-time. In RSCs, scalability refers to the extent to which a supply chain must meet new requirements in a short time frame, which depends on two factors: the latency, which represents the time necessary for finishing the product and its delivery to the end customer (From the reception of the request until the final delivery), as well as throughput, which is the count of products produced per time unit. Measuring scalability consists in combining the value of latency and average throughput related to the supply chain. In fact, the increase in throughput of production, delivery as well as the reduction in waiting times show the scalability high value. In fact, the latter involves reducing the latency time of the order also known as the total order cycle defined as the time elapsed since the receipt of the order until the product is delivered to the client. Besides, increased throughput in a supply chain leads to faster response time. This term is defined as the amount of product or service that a company can produce and provide within a specified time frame. It is often used to indicate the rate of production or the speed at which a product is processed.

$S$ indicates the degree of scalability which varies between 0 and 1 . It depends on the latency $L$ indicating the configuration latency in supply chain. This time is the ratio between the $T T$ throughput time which includes the execution process times (material transformation time, etc.), the control time, the transport time (internally and externally) and the waiting time before processing and moving activities, on the one hand, and delivery time noted $D T$, on the other hand. Thus, the second parameter $T$ represents the supply chain throughput capacity. $D e_{\max }$ and $D e_{\min }$ are respectively the maximum output product flow and the minimum output product in supply chain. The degree of scalability increases by adjusting the throughput time with the delivery cycle time, which involves reducing the waiting times in order to minimize the delivery cycle time. Moreover, increasing the actual capacity by adding resources allow reaching maximum capacity, which consequently increases the scalability of the supply chain.

$S=\frac{L+T}{2}$

$L=\frac{D T}{T T}$

$T=\frac{D e \min }{D e \max }$
Table 3 Scale for quantitative and qualitative judgments of visibility

\begin{tabular}{ll}
\hline Judgement & Value \\
\hline Quantity & $\begin{array}{l}\text { 1 If the company has poor accessibility to information related to supply chain stakeholders } \\
2 \text { If the company has high accessibility to information related to supply chain stakeholders }\end{array}$ \\
Precision & $\begin{array}{l}1 \text { If the accuracy of the information exchanged between the actors in the chain is low (the } \\
\text { information is often incorrect) }\end{array}$ \\
& $\begin{array}{l}2 \text { If the accuracy of the information exchanged between supply chain stakeholders is high } \\
\text { (the information is rarely incorrect) }\end{array}$ \\
Freshness & $\begin{array}{l}\text { If the freshness is low (information is not updated quickly) } \\
2 \text { If the freshness is high (information is updated quickly) }\end{array}$ \\
\end{tabular}




\section{Measurement of customization in RSCs}

The customization is defined by the degree to which the capability and flexibility of the supporting infrastructure for supply network match the application (supply chain activities) (Kelepouris et al., 2006). In supply chain, customization depends on product characteristics, partners characteristics and market characteristics (Zebardast et al., 2013). In the context of mass customization, it is important to focus on postponement strategies to quickly meet the increasing demand for more diverse products, which requires changing supply chain structures (Shahzad \& Hadj-Hamou, 2013).

Thus, customization depends on three factors: customer involvement, response time, and the degree of customer involvement. In fact, customer involvement is a key factor in measuring the degree of customization in the supply chain. It depends on the supply chain ability to delay product personalization/differentiation activities until the demand is known. The degree of customer involvement in the final product is a factor that allows measuring the number of customers looking for customized products, compared to the total number of customers.

The second factor which is the response time which must be minimized in order to reduce lead time (Graman, 2010). According to (Chandra \& Kamrani, 2004), order response time and product delivery are among the main performance measures used to evaluate the impact of mass customization.

The calculation of the number of customized functions/ features is a factor that measures the number of customization functions, compared to the total number of production functions in the chain, which represent the third factor. Indeed, a large and varied number of custom functions implies a higher degree of customization. The third factor considered in the customization measurement is the delivery time factor. It is a measure of the supply chain ability to meet the customer's desired delivery time.

$\mathrm{Cm}$ represents the degree of customization of the RSCs ranging from 0 to 1 . A value of $C m$ close to 1 indicates a high degree of customization. Its degree was measured using three factors. The first factor is the average number of customized features noted $F P_{p}$. It represents the ratio between the number of customized functions related to the product $p$ in the RSCs, noted $N F P_{p}$, and the number of the total functions of the product $p$ noted $N F_{p}$. The second factor is the number of customers implicated in customization noted $F C_{p}$. It is the ratio between the number of customers requiring a customized product $p$, noted $N C P_{p}$, and the total number of customers noted $N C_{p}$. The third factor is the delivery time factor noted $F D_{p}$. It is the ratio between the expected delivery time of the product $p$, noted $E D T_{p}$, and the actual delivery time $A D T_{p}$. The actual delivery time is the sum of order processing time $O P T_{p}$, production time $P T_{p}$ and delivery time $D T_{p}$ of the product $p$.

$$
\begin{aligned}
& C m=\frac{1}{N P} \sum_{p \in N P} F P_{p} \times F C_{p} \times F D_{p} \\
& F P_{p}=\frac{N F P_{p}}{N F_{p}} \\
& F C_{p}=\frac{N C P_{p}}{N C_{p}} \\
& F D_{p}=\frac{E D T_{p}}{A D T_{p}} \\
& A D T_{p}=O P T_{p}+P T_{p}+D T_{p}
\end{aligned}
$$

\section{The proposed reconfigurability index}

Based on the MAUT, the reconfigurability index consists in aggregating the proposed SCR measurements. According to MAUT, the evaluation of reconfigurability is defined by the function (29). $\mathrm{R}$ indicates the reconfigurability index ranging from 0 to $1 . \mathrm{w}_{\mathrm{M}}, \mathrm{w}_{\mathrm{Co}}, \mathrm{w}_{\mathrm{I}}, \mathrm{w}_{\mathrm{S}}, \mathrm{w}_{\mathrm{D}}, \mathrm{w}_{\mathrm{Cu}}$ represent respectively the relative weight of modularity, convertibility, integrability, scalability, diagnosability and customization. A value of $\mathrm{R}$ close to 1 indicates a high value of reconfigurability and a value of $R$ close to 0 shows a low value of $R$. Sensitivity analysis was used to assess the impact of each characteristic on the configuration choice.

$$
\begin{aligned}
& R=w_{M} M+w_{C o} C o+w_{I} I+w_{S} S+w_{D} D+w_{C u} C u \\
& w_{M}+w_{C o}+w_{I}+w_{S}+w_{D}+w_{C u}=1
\end{aligned}
$$

\section{Illustrative example}

An illustrative example is presented, in this section, to demonstrate the applicability of the proposed measurements. This example uses a global supply chain that consists of four processes: plan, purchasing, production and deliver. In fact, the plan process includes sourcing plan and distributing plan, while the purchasing process considers requirements identification, supplier selection and goods reception. On the other hand, the production process consists of product manufacturing and quality control. Finally, the deliver process deals with order receipt, order preparation and shipping, as shown in Fig. 2.

This example addresses a two echelons supply chain with three suppliers $(\mathrm{S})$, one plant $(\mathrm{P})$ and four retailers $(\mathrm{R})$. With 
the recent market changes that can affect the supply chain, we assume that, with the current configuration, the supply chain cannot guarantee product availability. Consequently, we propose to reconfigure the supply chain in order to cope with out-of-stock problems. Within this reconfiguration decision, two alternative configurations were considered, as revealed in Fig. 3. The first configuration, characterized by the addition of a new plant that will deliver final products to the distribution centers (DSs) before shipping to retailers, is called "Plant expansion". This configuration resulted in an increase in production capacity, which guarantees the product availability at the distribution centers. The second configuration, characterized by the addition of two DSs, is called "Distribution center expansion". Indeed, the final customization operations would be relocated to the distribution centers in order to reduce lead-time and response time.

\section{Modularity degree}

Each process consists of a set of activities performed to accomplish supply chain objectives. In order to measure the degree of modularity of the new configurations, the supply chain was decomposed into a set of modules based on the Design Structure Matrix (DSM) method, as shown in Fig. 4. The clustering of the supply chain activities requires the determination of the inbound and outbound flows. For this reason, the scale proposed by (Chen and Huang, 2007) was used. For example, the inventory activity requires physical input and information input from distribution plan activity, product realization activity and shipping activity with a degree of interaction of 50\%, $40 \%$ and $60 \%$, respectively. The DSM can be re-arranged to obtain cluster of activities having high interactions. This clustering allows obtaining the minimum interactions between modules called intermodules and maximum intra-module interactions. Some activities cannot be clustered in the same module even if they are highly interconnected, because they cannot be performed
(Suppliers) (Plant) (Customers)

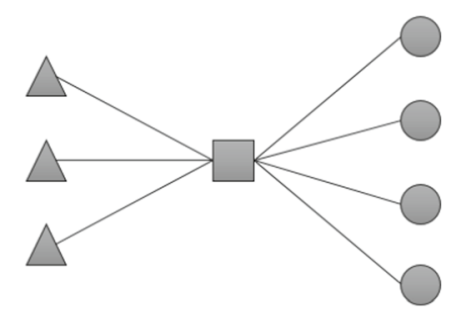

(a)

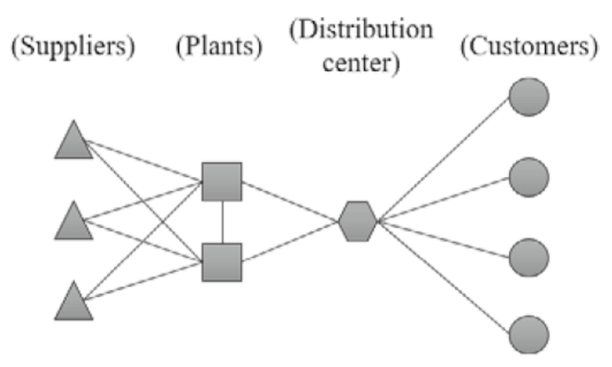

(b)

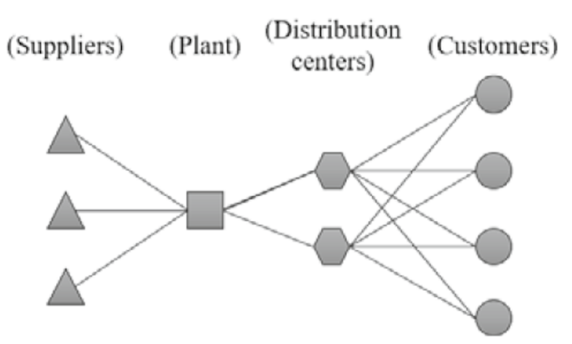

(c)

Fig. 3 The current configuration (a), the first alternative configuration (b), the second alternative configuration (c)
Fig. 2 Supply chain processes and activities

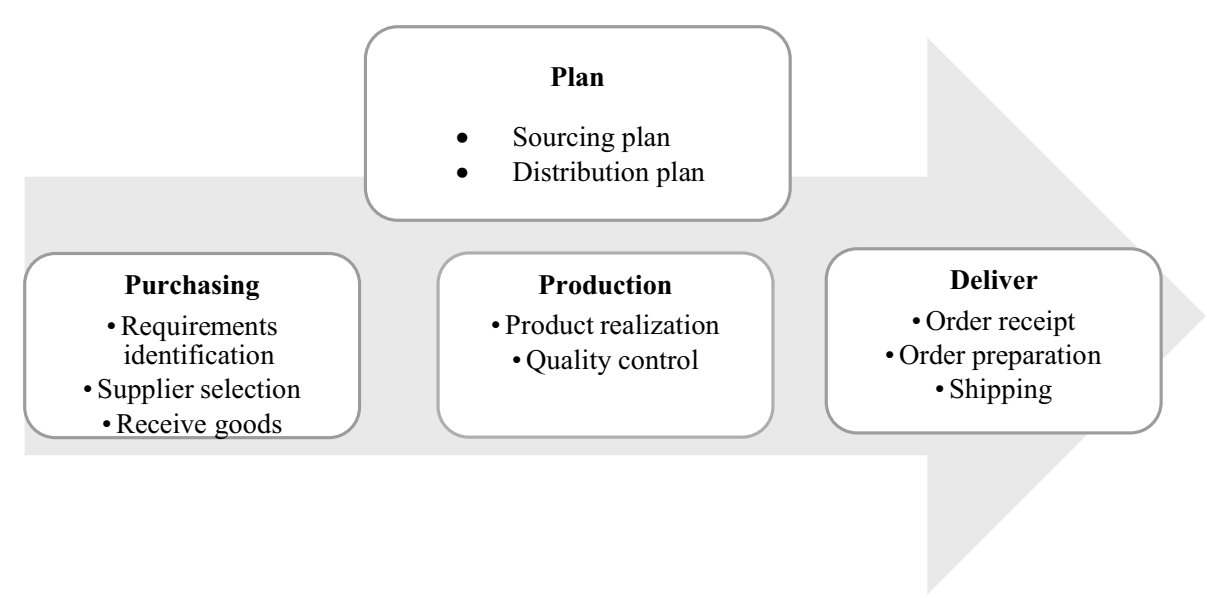


(a)

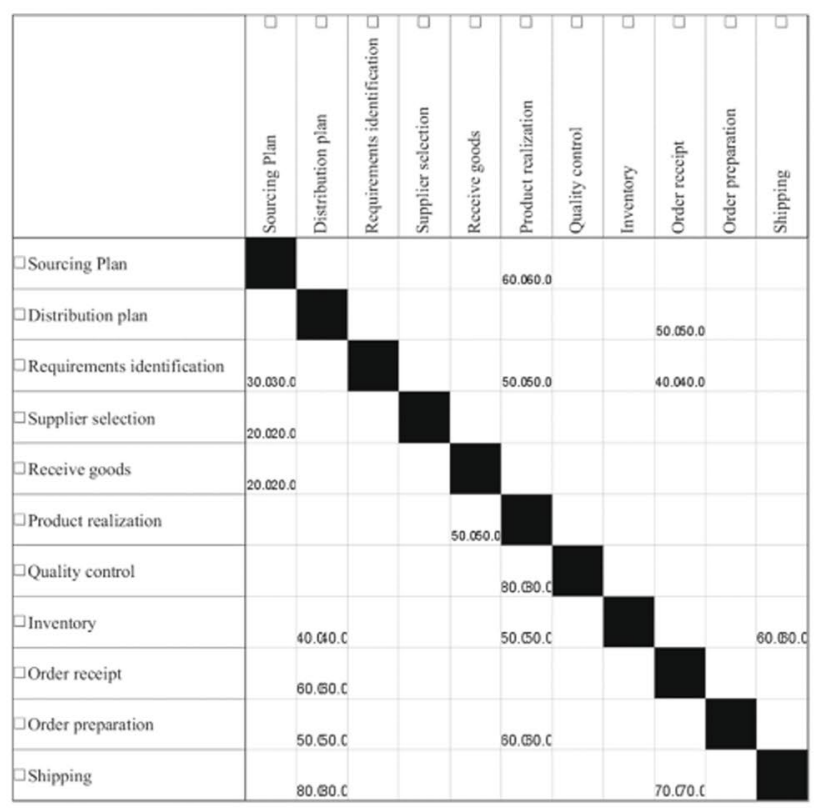

(b)

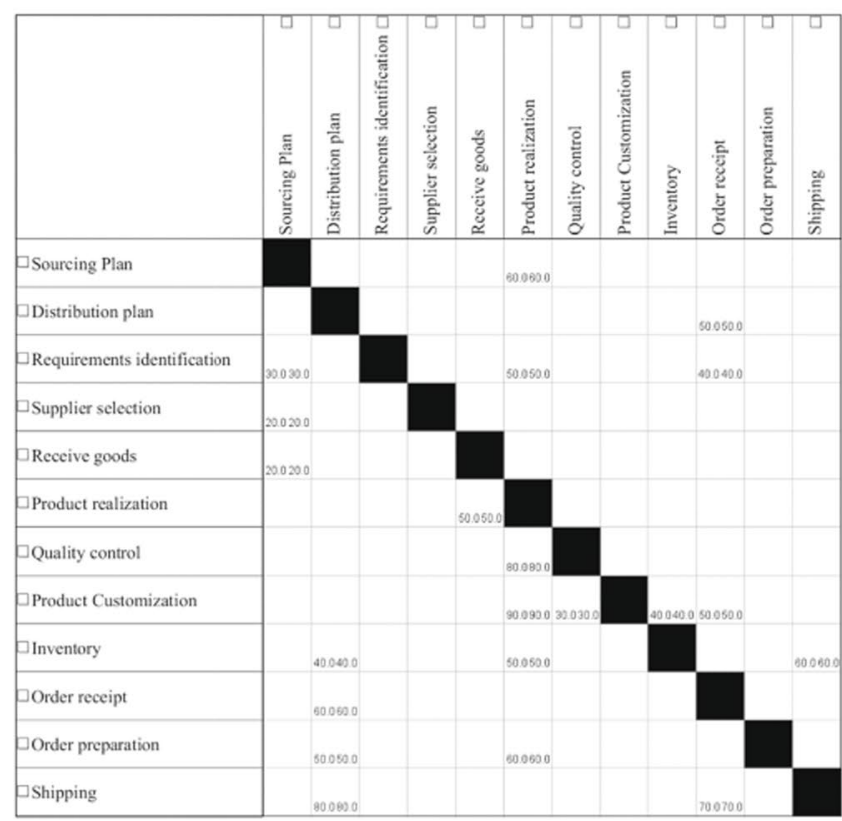

Fig. 4 Modular design of the alternative configurations. a Interactions determined for the first alternative configuration, $\mathbf{b}$ Interactions determined for the second alternative configuration, $\mathbf{c}$ Modular design

in the same location or they are not of the same type. The obtained results of intra-modules and inter-modules for the two alternatives are summarized in Tables 4 and 5. (c)

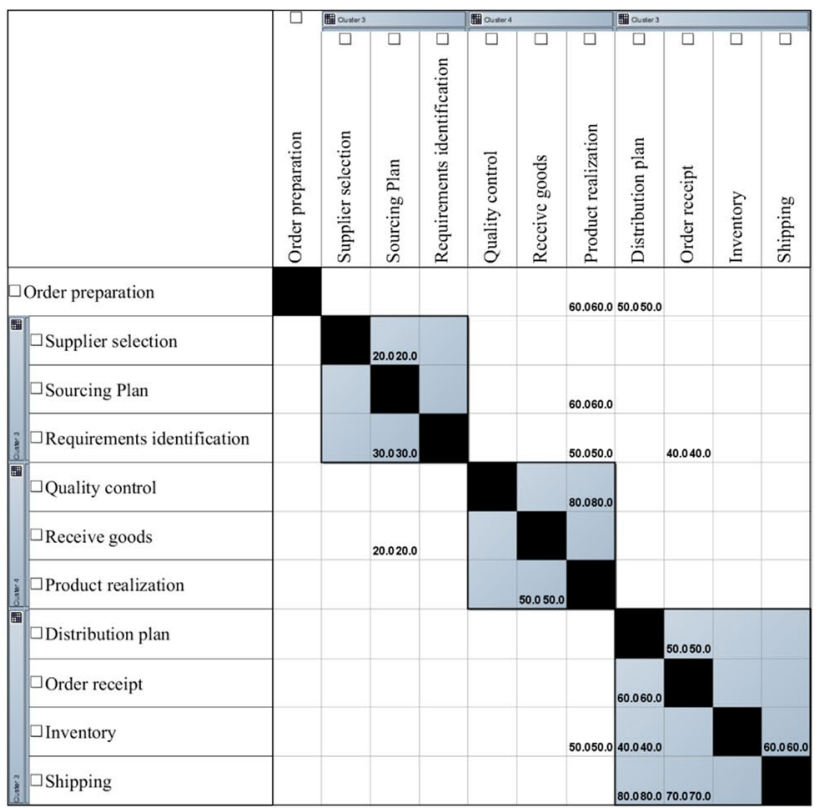

(d)

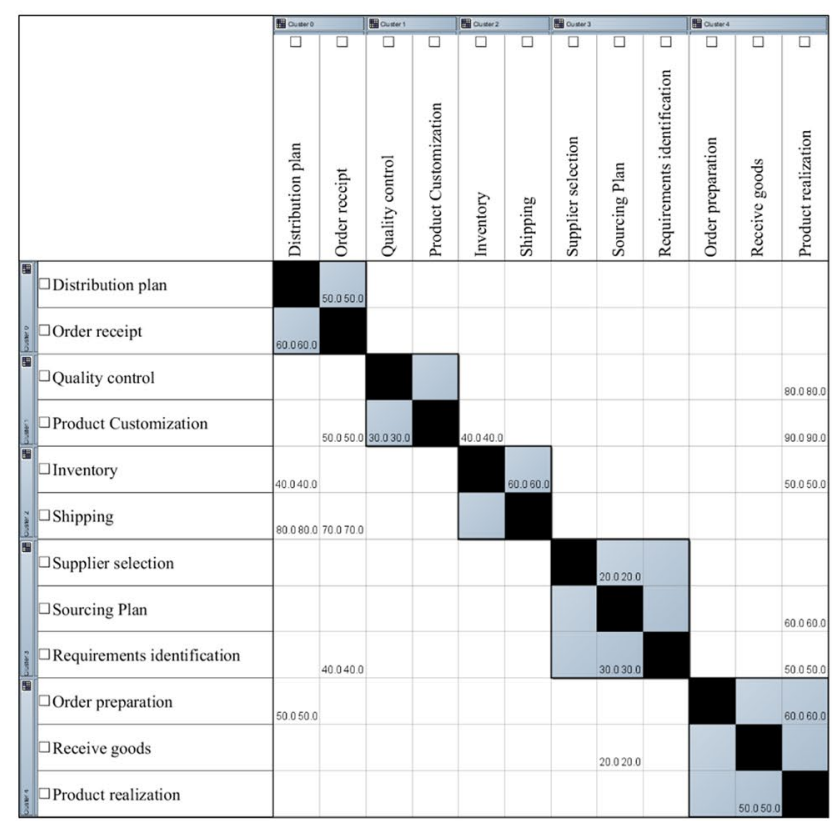

of the first alternative configuration, $\mathbf{d}$ Modular design of the second alternative configuration

\section{Integrability degree}

The degree of integrability depends on the supply chain complexity measured by the number of connections and the number of nodes. For the first alternative, the three suppliers will deliver to both plants where the number of connections is equal to 13 . The estimated reconfiguration time 
Table 4 The obtained results for modularity measurement of the first alternative

\begin{tabular}{lllllllllllll}
\hline & Ri & Di & DIi & DIi + X & PIi & Ai & Ei & Ai/TAi & Ei/TEi & Ei/TEi*PIi & Ia & Ie \\
\hline M1 & 0 & 1.1 & -1.1 & 0.2 & 0.04 & 0 & 2 & 0.00 & 0.10 & 0.003846 & 0.2916 & 0.0062 \\
M2 & 0.2 & 1.5 & -1.3 & 0 & 0 & 2 & 4 & 0.33 & 0.08 & 0 & & \\
M3 & 2.2 & 0.2 & 2 & 3.3 & 0.63 & 2 & 1 & 0.33 & 0.02 & 0.013221 & & \\
M4 & 0.9 & 0.5 & 0.4 & 1.7 & 0.33 & 6 & 1 & 0.50 & 0.02 & 0.007784 & & \\
$\sum$ & & & & 5.2 & & & & 1.17 & & 0.024851 & & \\
\hline
\end{tabular}

Table 5 The obtained results for modularity measurement of the second alternative

\begin{tabular}{|c|c|c|c|c|c|c|c|c|c|c|c|c|}
\hline & $\mathrm{Ri}$ & Di & DIi & $\mathrm{DIi}+\mathrm{X}$ & PIi & $\mathrm{Ai}$ & $\mathrm{Ei}$ & $\mathrm{Ai} / \mathrm{TAi}$ & Ei/ TEi & Ei/TEi*PIi & Ia & $\mathrm{Ie}$ \\
\hline M1 & 3.3 & 0 & 3.3 & 5.9 & 0.44 & 2 & 6 & 1.00 & 0.15 & 0.065556 & 0.4666 & 0.0265 \\
\hline M2 & 0 & 2.6 & -2.6 & 0 & 0.00 & 1 & 4 & 0.50 & 0.10 & 0 & & \\
\hline M3 & 0.4 & 2.4 & -2 & 0.6 & 0.04 & 1 & 5 & 0.50 & 0.13 & 0.005556 & & \\
\hline M4 & 0.2 & 1.5 & -1.3 & 1.3 & 0.10 & 2 & 4 & 0.33 & 0.07 & 0.007133 & & \\
\hline M5 & 3.3 & 0.2 & 3.1 & 5.7 & 0.42 & 2 & 7 & 0.33 & 0.13 & 0.054733 & & \\
\hline$\sum$ & & & & 13.5 & & & & 2.33 & & 0.132977 & & \\
\hline
\end{tabular}

Table 6 The obtained results for integrability measurement

\begin{tabular}{lll}
\hline & First alternative & Second alternative \\
\hline Reconfiguration time & 1 year & 2 months \\
Total cycle time & 2 years & 6 months \\
Reconfiguration cost & $1,000,000 €$ & $15,000 €$ \\
Total cost & $1,500,000 €$ & $2,000,000 €$ \\
$\begin{array}{l}\text { Total number of connec- } \\
\text { tions between nodes }\end{array}$ & 13 & 9 \\
Total number of nodes & 10 & 10 \\
\hline
\end{tabular}

for the first alternative configuration is 1 year which can be considered as a high time. Thus, the average cost of the reconfiguration for the first configuration is very important, compared to that for the second configuration because, with only one warehouse, the failure of the supply chain will generate other costs that will decrease the cost-effectiveness of this reconfiguration, as demonstrated in Table 6.

\section{Convertibility degree}

The degree of convertibility was measured from the redundancy of entities. The matrices shown in Tables 7 and 8 show the redundant activities, i.e. those which are dependent on other activities. For example, in Table 7, the sourcing plan activity contributes to the realization of the requirements
Table 7 Matrix of the activity redundancy of the first configuration

\begin{tabular}{|c|c|c|c|c|c|c|c|c|c|c|c|c|}
\hline & & 1 & 2 & 3 & 4 & 5 & 6 & 7 & 8 & 9 & 10 & 11 \\
\hline Sourcing Plan & 1 & & 0 & 1 & 1 & 0 & 0 & 0 & 0 & 0 & 0 & 0 \\
\hline Distribution plan & 2 & 0 & & 0 & 0 & 0 & 0 & 0 & 0 & 1 & 1 & 1 \\
\hline Requirements identification & 3 & 1 & 0 & & 1 & 0 & 1 & 1 & 0 & 0 & 0 & 0 \\
\hline Supplier selection & 4 & 1 & 0 & 1 & & 0 & 1 & 1 & 0 & 0 & 0 & 0 \\
\hline Receive goods & 5 & 0 & 0 & 0 & 0 & & 1 & 1 & 0 & 1 & 0 & 0 \\
\hline Product realization & 6 & 0 & 0 & 1 & 1 & 1 & & 1 & 0 & 1 & 0 & 0 \\
\hline Quality control & 7 & 0 & 0 & 1 & 1 & 1 & 1 & & 0 & 1 & 0 & 0 \\
\hline Inventory & 8 & 0 & 0 & 0 & 0 & 0 & 0 & 0 & & 1 & 0 & 1 \\
\hline Order receipt & 9 & 0 & 1 & 0 & 0 & 1 & 1 & 1 & 1 & & 1 & 1 \\
\hline Order preparation & 10 & 0 & 1 & 0 & 0 & 0 & 0 & 0 & 0 & 1 & & 1 \\
\hline Shipping & 11 & 0 & 1 & 0 & 0 & 0 & 0 & 0 & 1 & 1 & 1 & \\
\hline$\sum_{j=1}^{N A} \sum_{k=1}^{N A} N a_{j k}$ & 2 & 3 & 4 & 4 & 3 & 5 & 5 & 2 & 7 & 3 & 4 & \\
\hline$\frac{\sum_{j=1}^{N A} \sum_{k=1}^{N A} N a_{j k}}{N_{a}-1}$ & 0.20 & 0.30 & 0.40 & 0.40 & 0.30 & 0.50 & 0.50 & 0.20 & 0.70 & 0.30 & 0.40 & \\
\hline
\end{tabular}


Table 8 Matrix of the activity redundancy of the second configuration
Table 9 Resources redundancy for the two alternatives

\begin{tabular}{llllllllllllll}
\hline & & 1 & 2 & 3 & 4 & 5 & 6 & 7 & 8 & 9 & 10 & 11 & 12 \\
\hline Sourcing Plan & 1 & & 1 & 1 & 1 & 1 & 1 & 0 & 0 & 0 & 1 & 1 & 0 \\
Distribution plan & 2 & 1 & & 1 & 1 & 0 & 1 & 0 & 0 & 0 & 1 & 1 & 1 \\
Requirements identification & 3 & 1 & 1 & & 0 & 1 & 1 & 1 & 0 & 0 & 0 & 0 & 0 \\
Supplier selection & 4 & 1 & 1 & 0 & & 0 & 1 & 1 & 0 & 0 & 1 & 0 & 0 \\
Receive goods & 5 & 1 & 0 & 1 & 0 & & 1 & 1 & 0 & 0 & 0 & 0 & 0 \\
Product realization & 6 & 1 & 1 & 1 & 1 & 1 & & 1 & 0 & 0 & 0 & 0 & 0 \\
Quality control & 7 & 0 & 0 & 1 & 1 & 1 & 1 & & 0 & 0 & 0 & 0 & 0 \\
Product Customization & 8 & 0 & 0 & 0 & 0 & 0 & 0 & 0 & & 0 & 0 & 0 & 0 \\
Inventory & 9 & 0 & 0 & 0 & 0 & 0 & 0 & 0 & 0 & & 0 & 0 & 0 \\
Order receipt & 10 & 1 & 1 & 0 & 1 & 0 & 0 & 0 & 0 & 0 & & 1 & 1 \\
Order preparation & 11 & 1 & 1 & 0 & 0 & 0 & 0 & 0 & 0 & 0 & 1 & & 1 \\
Shipping & 12 & 0 & 1 & 0 & 0 & 0 & 0 & 0 & 0 & 0 & 1 & 1 & \\
$\sum_{j=1}^{N A} \sum_{k=1}^{N A} N a_{j k}$ & 7 & 7 & 5 & 5 & 4 & 6 & 4 & 0 & 0 & 5 & 4 & 3 & \\
$\sum_{j=1}^{N A} \sum_{k=1}^{N A} N a_{j k}$ & & & & & & & & & & & & & \\
\hline
\end{tabular}

\begin{tabular}{|c|c|c|c|c|}
\hline & \multicolumn{2}{|l|}{ First alternative } & \multicolumn{2}{|l|}{ Second alternative } \\
\hline & $\begin{array}{l}\text { Number of redun- } \\
\text { dant resources }\end{array}$ & $\begin{array}{l}\text { Total number of } \\
\text { resources }\end{array}$ & $\begin{array}{l}\text { Number of redun- } \\
\text { dant resources }\end{array}$ & $\begin{array}{l}\text { Total } \\
\text { number of } \\
\text { resources }\end{array}$ \\
\hline Sourcing Plan & - & - & - & - \\
\hline Distribution plan & - & - & - & - \\
\hline Requirements identification & - & - & - & - \\
\hline Supplier selection & 2 & 3 & 2 & 5 \\
\hline Receive goods & - & - & - & - \\
\hline Product realization & 3 & 3 & 1 & 3 \\
\hline Quality control & - & - & - & - \\
\hline Product Customization & - & - & 3 & 3 \\
\hline Inventory & 1 & 3 & 3 & 3 \\
\hline Order receipt & 4 & 6 & 8 & 9 \\
\hline Order preparation & 1 & 3 & 5 & 6 \\
\hline Shipping & 1 & 3 & 6 & 6 \\
\hline
\end{tabular}

identification and supplier selection activities. Table 9 shows the redundant resources that can be:

- Material resources which concern the transport vehicles, machines, i.e. the redundancy related to the number of capacity, destination, etc.

- Immaterial resources which include, for example, data redundancy referring to the availability of identical data in different databases at various levels and workforce versatility.
Table 10 The obtained results for convertibility measurement

\begin{tabular}{lll}
\hline & First alternative & $\begin{array}{l}\text { Second } \\
\text { alternative }\end{array}$ \\
\hline Resource convertibility & 0.70 & 0.52 \\
Activity convertibility & 0.64 & 0.64 \\
Functional convertibility & 0.67 & 0.58 \\
Connection redundancy rate & 0.20 & 0.20 \\
Node redundancy rate & 0.38 & 0.77 \\
Structural convertibility & 0.29 & 0.48
\end{tabular}

The obtained results are summarized in Table 10 . 


\section{Diagnosability degree}

For diagnosability measurement, we identified the failure detection time for both configurations, as illustrated in Table 11. Indeed, this time depends on the type of failure (receiving a faulty product, non-respect of deadlines with suppliers, sending a bad product to the end customer, etc.) which requires one day to determine the source of failure. Then, the cycle time of the node includes process operating time, control times, transport times, waiting times, etc.

\section{Scalability degree}

Scalability measurement was determined based on throughput time and latency. Indeed, the first supply chain configuration requires two working days for order fulfillment; from order reception until its delivery to the retailers out of a total of ten days. This throughput time is a very high time. As a result, the supply chain throughput reached 30 orders per day, as shown in Table 12. For the first alternative configuration, the addition of a new plant increased supply chain throughput. But, with one distribution center, it was difficult to reduce the order delivery time. On the other hand, the addition of two distribution centers minimized the delivery time and increased the supply chain throughput by increasing the storage capacity.

\section{Customization degree}

In the first alternative configuration, the company could not offer customized products because of their high cost and lead-time. In the first alternative, with the addition of another plant and a distribution center, the was able to increase its production capacity and guarantee the products' availability to retailers, as shown in Table 13. Therefore,

Table 11 The obtained results for diagnosability measurement

\begin{tabular}{|c|c|c|c|c|}
\hline & \multicolumn{2}{|c|}{ First alternative } & \multicolumn{2}{|c|}{ Second alternative } \\
\hline & Echelon 1 & Echelon 2 & Echelon 1 & Echelon 2 \\
\hline Detection time of the echelon e & 1 day & 1 day & 1 day & 1 day \\
\hline Cycle time of the echelon e & 5 days & 5 days & 3 days & 3 days \\
\hline Judgement on the quantity of information about the internal flows of the echelon e & 1 & 1 & 1 & 1 \\
\hline Judgement on the quantity of information about the external flows of the echelon e & 1 & 2 & 1 & 2 \\
\hline Judgement on the accuracy of information about the internal flows of the echelon e & 1 & 2 & 1 & 2 \\
\hline Judgement on the accuracy of information about the external flows of the echelon e & 1 & 2 & 1 & 2 \\
\hline Judgement on the freshness of information about the internal flows of the echelon e & 1 & 2 & 1 & 2 \\
\hline Judgement on the freshness of information about the external flows of the echelon e & 1 & 2 & 1 & 2 \\
\hline
\end{tabular}

Table 12 The obtained results for scalability measurement

\begin{tabular}{lll}
\hline & First alternative & Second alternative \\
\hline Throughput time in the supply chain & 2 days & $1 / 2$ day \\
Delivery time in the supply chain & 5 days & 1 day \\
Maximum product throughput in the supply chain & 30 units & 60 units \\
Minimum product throughput in the supply chain & 10 units & 45 units \\
\hline
\end{tabular}

Table 13 The obtained results for customization measurement

\begin{tabular}{|c|c|c|c|c|}
\hline & \multicolumn{2}{|c|}{ First alternative } & \multicolumn{2}{|c|}{ Second alternative } \\
\hline & Product 1 & Product 2 & Product 1 & Product 2 \\
\hline Number of customization functions for product $p$ & 1 & 1 & 3 & 3 \\
\hline Total number of functions involved in the production of the product $p$ & 5 & 6 & 5 & 6 \\
\hline Number of customers requesting the customized product $p$ & 50 & 20 & 70 & 80 \\
\hline Total number of customers requesting the product $\mathrm{p}$ & 150 & 80 & 70 & 80 \\
\hline Delivery time desired by the customer for the customized product $p$ & 6 days & 2 days & 3 days & 2 days \\
\hline Real delivery time of customized product $\mathrm{p}$ & 7 days & 3 days & 4 days & 2 days \\
\hline
\end{tabular}


the supply chain was able to offer customization activity performed in distribution center. For the second alternative, with two distribution centers, the supply chain was able to offer a wider range of customized products with a lower response time compared to that of the first alternative.

\section{Reconfigurability index}

Assigning weights to reconfigurability characteristics depends on the choice of decision-makers. Their preferences were determined according to reconfiguration objectives and market needs. In this example, the data of weights for the two alternatives is randomly generated using Excel.

The aggregation of these weights with the provided results of SCR characteristic measurements allowed obtaining the degree of reconfigurability for the two alternatives. Based on the weight distribution results listed in Table 14, the evaluation of the two alternatives was carried out using Eq. (29).

\section{Results and discussion}

The calculation results show that the values of the six characteristics are more important in the first alternative configuration than in the second alternative configuration, as revealed in Table 15, with a GAP exceeding 50\% for customization, diagnosability and integrability. The scalability achieves a GAP of $41 \%$. The modularity has a GAP of $11 \%$. Thus, we may deduce that convertibility is the characteristic with the lowest gap which is $10 \%$. The gap calculation allowed comparing the degree of each characteristic for the two alternatives. Indeed, we notice an important difference between the characteristics with a GAP higher than $50 \%$.

The degree of modularity of the first configuration alternative is higher than the second alternative thanks to the increase of the intra-modules value. In fact, with two distribution centers, the supply chain was able to
Table 15 The degree of SCR characteristics obtained for the two alternatives

\begin{tabular}{llll}
\hline & $\begin{array}{l}\text { First alternative } \\
\text { configuration }\end{array}$ & $\begin{array}{l}\text { Second alternative } \\
\text { configuration }\end{array}$ & Gap \\
\hline Modularity & 0.643 & 0.720 & $11 \%$ \\
Integrability & 0.242 & 0.816 & $70 \%$ \\
Convertibility & 0.480 & 0.533 & $10 \%$ \\
Diagnosability & 0.134 & 0.377 & $64 \%$ \\
Scalability & 0.367 & 0.625 & $41 \%$ \\
Customization & 0.085 & 0.475 & $82 \%$ \\
\hline
\end{tabular}

$\mathrm{Gap}=(($ Second alternative configuration value- - first alternative configuration value)/second alternative configuration value)*100

ensure higher degree of independency. This modular design increased the degree of customization because, in the second configuration, the customization functions were performed in the distribution centers. We note that modularity and personalization were highly dependent. A high modularity close to 1 allowed to reducing the lead time of the supply chain, on the one hand, by increasing the degree of intra-modules and reducing the degree of inter-modules. On the other hand, a modular design of the supply chain also minimizes the response time for customized products. The rise in the customization functions (whether of products or services), thanks to the implementation of two distribution centers, resulted in the increase of the customization degree for the second alternative. Moreover, with the implementation of two distribution centers, the supply chain was able to increase its customer portfolio and, therefore, rising the customers requesting customized products. Thus, we may deduce that the increase of customization functions may affect positively the customization degree. In other words, with the new distribution centers, the supply chain was able to offer more customization functions that would be performed in these centers. This value increased due to the reduction of the detection time as well as the cycle time through
Table 14 Weights generated for the SCR characteristics

\begin{tabular}{lllllll}
\hline & Modularity & Integrability & Convertibility & Diagnosability & Scalability & Customization \\
\hline Instance (1) & 0.216 & 0.288 & 0.099 & 0.139 & 0.107 & 0.161 \\
Instance (2) & 0.103 & 0.130 & 0.168 & 0.269 & 0.209 & 0.121 \\
Instance (3) & 0.300 & 0.065 & 0.090 & 0.270 & 0.163 & 0.111 \\
Instance (4) & 0.200 & 0.123 & 0.176 & 0.022 & 0.199 & 0.280 \\
Instance (5) & 0.313 & 0.103 & 0.116 & 0.022 & 0.025 & 0.420 \\
Instance (6) & 0.114 & 0.204 & 0.106 & 0.062 & 0.113 & 0.400 \\
Instance (7) & 0.023 & 0.347 & 0.063 & 0.333 & 0.115 & 0.120 \\
Instance (8) & 0.143 & 0.186 & 0.287 & 0.130 & 0.176 & 0.078 \\
Instance (9) & 0.085 & 0.453 & 0.143 & 0.152 & 0.003 & 0.164 \\
Instance (10) & 0.167 & 0.203 & 0.057 & 0.021 & 0.186 & 0.366 \\
\hline
\end{tabular}


Fig. 5 Measurement of the reconfigurability characteristics in the proposed example

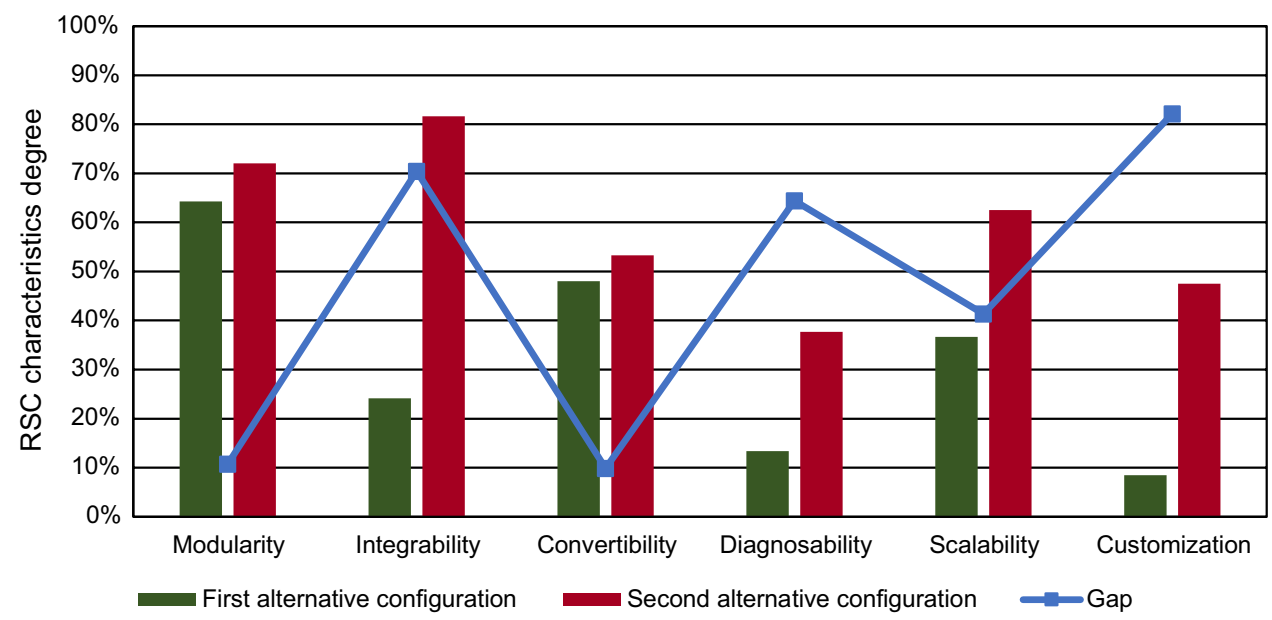

Table 16 The obtained results of the degree of reconfigurability

\begin{tabular}{lll}
\hline & \multicolumn{2}{l}{ Reconfigurability index } \\
\cline { 2 - 3 } & $\begin{array}{l}\text { First alternative configu- } \\
\text { ration }\end{array}$ & $\begin{array}{l}\text { Second alterna- } \\
\text { tive configura- } \\
\text { tion }\end{array}$ \\
\hline Instance (1) & 0.320 & 0.631 \\
Instance (2) & 0.301 & 0.559 \\
Instance (3) & 0.357 & 0.574 \\
Instance (4) & 0.342 & 0.604 \\
Instance (5) & 0.330 & 0.595 \\
Instance (6) & 0.257 & 0.590 \\
Instance (7) & 0.226 & 0.587 \\
Instance (8) & 0.363 & 0.603 \\
Instance (9) & 0.268 & 0.644 \\
Instance (10) & 0.286 & 0.614 \\
\hline
\end{tabular}

the increase of the visibility degree. In fact, the rise of scalability degree in the second alternative configuration was due to the decrease of the total delivery time which allowed increasing the supply chain throughput. Obviously, the reduction in the number of connections in the second configuration reduced the supply chain complexity. Indeed, using the modular design, it was possible to ensure interdependency between supply chain activities and reduce the supply chain complexity. It is also clear that the implementation of two distribution centers increased the supply chain' ability to ensure product availability for retailers and guaranteed more customization functions that can be performed in the distribution centers to minimize the response time.

By rising the degree of each SCR characteristics, the degree of reconfigurability can be increased. From Fig. 5, better reconfigurability supply chain degree, indicated by a high degree of modularity, integrability, convertibility,
Table 17 The new degrees of RSC characteristics

\begin{tabular}{lll}
\hline & $\begin{array}{l}\text { First alternative con- } \\
\text { figuration }\end{array}$ & $\begin{array}{l}\text { Second alterna- } \\
\text { tive configura- } \\
\text { tion }\end{array}$ \\
\hline Modularity & 0.651 & 0.450 \\
Integrability & 0.589 & 0.464 \\
Convertibility & 0.317 & 0.813 \\
Diagnosability & 0.462 & 0.207 \\
Scalability & 0.412 & 0.069 \\
Customization & 0.234 & 0.932 \\
\hline
\end{tabular}

diagnosability and scalability, were observed. Moreover, the obtained results show the dependency between the assigned weights for each characteristics and the degree of reconfigurability. Table 16 shows the different variations in reconfigurability degrees. The experimental findings reveal that the second alternative had greater degrees of modularity, integrability, convertibility, diagnosability, scalability and customization. The variation in the assigned weights demonstrates that the choice of the best configuration was not affected by the variation in the assigned weights.

Based on the data listed in Table 16, the alternative reconfigurability degrees are modified according to the new degrees of modularity, integrability, convertibility, diagnosability, scalability and customization. These values were randomly generated using EXCEL in order to assess the impact of each characteristics degrees on the reconfigurability index.

The aggregation of the new RSC characteristics with the identified weights, shown in Table 15, gave the results shown in Table 17. These findings demonstrate that the reconfigurability index depends on the RSC characteristic degrees. For the first alternative, the modularity increased significantly, while the degree of convertibility decreased 
by $33.95 \%$. The degree of integrability, diagnosability, scalability and customization rose by more than $12.26 \%$. These important increases affected the reconfigurability index for the 10 instances, which augmented by a minimum percentage of $22 \%$. Besides, the reconfigurability index of instance 7 increased by $107 \%$. This improvement was due to the increase of the above-mentioned indicators. For the second alternative, the convertibility and the customization augmented by $34 \%$ and $49 \%$, respectively. However, the degrees of modularity, integrability, diagnosability and especially the scalability decreased with a minimum percentage of $60 \%$. As shown in Table 18, this decrease of the mentioned characteristics affected negatively the reconfigurability index. However, only instances 5 and 6 achieved an increase in their degree of reconfigurability.

From this analysis, we can conclude that the variation of the assigned weight values for each characteristic did not affect the choice of the best configuration. Results, presented in Table 16, show that the second alternative remains the

Table 18 Evaluation of reconfigurability index of the two alternatives

\begin{tabular}{lll}
\hline & \multicolumn{2}{l}{ Reconfigurability index } \\
\cline { 2 - 3 } & $\begin{array}{l}\text { First alternative configu- } \\
\text { ration }\end{array}$ & $\begin{array}{l}\text { Second alterna- } \\
\text { tive configura- } \\
\text { tion }\end{array}$ \\
\hline Instance (1) & 0.481 & 0.493 \\
Instance (2) & 0.436 & 0.426 \\
Instance (3) & 0.480 & 0.409 \\
Instance (4) & 0.416 & 0.570 \\
Instance (5) & 0.420 & 0.682 \\
Instance (6) & 0.397 & 0.626 \\
Instance (7) & 0.468 & 0.411 \\
Instance (8) & 0.444 & 0.496 \\
Instance (9) & 0.477 & 0.550 \\
Instance (10) & 0.418 & 0.574 \\
\hline
\end{tabular}

best configuration even when the weights changed. However, the identification of preferences is crucial in the reconfigurability assessment process, because it is important to identify the most important characteristics in order to prioritize the reconfiguration objectives. On the contrary, the variation in the degrees of reconfigurability characteristics affected the final value of the reconfigurability index, as shown in Fig. 6. Their increase allowed obtaining high level of reconfigurability. Therefore, it is important to achieve degrees of reconfigurability close to 1 to have a more reconfigurable supply chain. The choice of the best configuration is a decision support process based on the evaluation of each configuration by measuring the modularity, integrability, convertibility, diagnosability, scalability and customization. The MAUT method enabled the aggregation of these six characteristics by assigning, to each one, a degree of importance according to the preferences of the decision-makers.

\section{Managerial implications}

Managers find themselves in a situation where they must choose the best alternatives of supply chain configuration by using some predefined criteria. This approach offers advantages to decision makers by assisting them to improve their supply chains. The market variations and disruptions that can affect the performance of the supply chain trigger the need to implement indicators that allow, on the one hand, evaluating the capacity of the supply chain to cope with unexpected events and, on the other hand, choosing the best configuration with the highest reconfigurability, i.e. the configuration that can easily adjust its structure and functions with the new changes.

The aim of this study is to help companies choose the best configuration that allows managers to respond more quickly to the market changes. The proposed approach suggests that the assessment of the supply chain ability to cope with disruptions is difficult and requires easily measurable indicators to judge this ability. By applying the introduced approach,
Fig. 6 The degree of reconfigurability with variation of the RSC characteristics

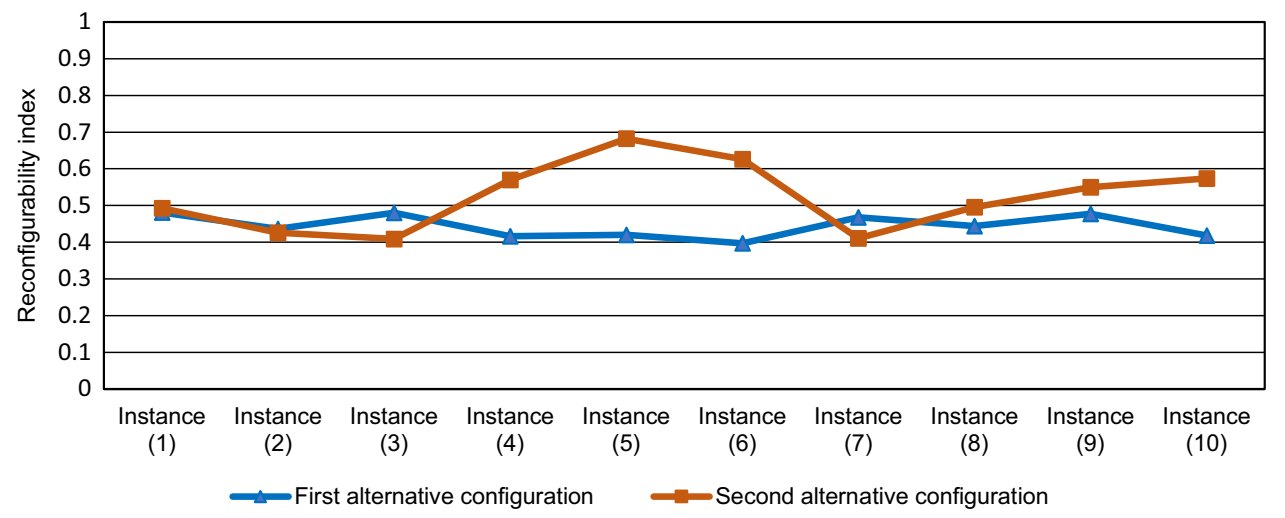


managers will be able to evaluate the ability of their supply chains to react rapidly to unexpected events. Indeed, the evaluation of reconfigurability represents an efficient way to choose the configuration that will be modular, able to convert its components, easily integrate new products as well as novel technologies and able to respond quickly to customer requirements with a strong customization. With the changes that can affect the supply chain, it is necessary to implement performance indicators to evaluate easily and effectively the ability of the supply chain to adapt its structure and functions with the new changes.

In fact, managers need to give more attention to implementing a modular, convertible, integrable, diagnosable, scalable and customizable supply chain. Obviously, the modularity of the supply chain ensures independence between the different activities of the supply chain and reduces the total lead time. The convertibility of the supply chain allows also reacting rapidly in case of disruption by ensuring redundancy in order to avoid downtime. To easily integrate new technologies, resources and actors, managers must minimize the complexity of their supply chains to ensure integrability. Supply chain scalability guarantees the adaptation of the supply chain capacity to the customers' needs with the minimum lead time by increasing its throughput. The guarantee of supply chain diagnosability allows the rapid detection of sources of failure by increasing the visibility of information flows. Finally, to rise the customization of the supply chain, the customer portfolio requesting customized products and the customization functions should be increased to offer more choices to customers. Hence, with this approach, managers will be able to implement a supply chain that easily adjusts its structure and functions with the market changes.

The application of this approach in real life is quite possible. Indeed, all the parameters chosen to evaluate modularity, integrability, convertibility, diagnosability, scalability and customization, were chosen so that the configuration enabling to quickly cope with disruptions can be easily determined. For example, with the COVID 19 crisis, some medical mask manufacturing companies were unable to handle the large demand increase, resulting in shortages of medical masks in several countries. This disruption revealed the necessity of using to assess the ability of the supply chain to cope with disruptions. Thus, the proposed measures can be easily applied to evaluate the ability of the supply chain to react quickly to disruptions. The usability and feasibility of our approach were demonstrated through the ease of obtaining the data needed to measure the introduced indicators.

\section{Conclusion and perspectives}

In this paper, we presented an index of reconfigurability based on the measurement of RSC characteristics. These proposed measurements were performed to evaluate the degree of reconfigurability in supply chain. The design of a RSC requires an indicator to choose the best configuration that meets the new market requirements. Therefore, the assessment of reconfigurability is an important phase that should be applied to improve the supply chain in a changing environment.

In the presented work, the different configurations in supply chain were compared based on a reconfigurability index. First, we proposed quantitative measures for modularity, integrability, convertibility, diagnosability, scalability and customization. Indeed, modularity ensured the independence between supply chain activities and allowed reducing the lead time. Increasing the degree of integrability implies reducing minimizing the degree of supply chain complexity. Convertibility required increasing the degree of redundancy of supply chain resources to facilitate the modification of the logistic chain. Increasing flow visibility provided a high degree of diagnosability. It was noticed that capability requires improving the average supply chain throughput by reducing the delivery time. Besides, the enhancement in the degree of customization involves increasing the number of functions related to customization and the number of customers requesting customized products. Indeed, the improvement of all these factors contributed to the increase in the degree of supply chain reconfigurability. Second, an index of reconfigurability was developed using the MAUT method which allowed assigning weights to each characteristic, comparing the different possible configurations and choosing the best one with the highest degree of reconfigurability. The results obtained from the applied example confirmed the above-described interpretations.

The proposed approach has two main limitations. First, it does not take into account the uncertainty and imprecision of the collected information, which may affect the judgment of the decision-maker on the choice of the best configuration. Second, With the proposed model, it is difficult to determine which reconfigurability characteristics can better improve the degree of reconfigurability. Thus, it will be interesting to analyze the impact of the six characteristics mentioned before on the improvement of reconfigurability.

The choice of the configuration with the highest degree of reconfigurability requires the consideration of imprecisions and uncertainties. Future studies could fruitfully explore this issue further by considering the uncertainty in the evaluation process. As recommended above, future research should consider the reconfigurability, resilience and viability to evaluate the ability of supply chain to deal with disruptions. 
Resilience is essentially related to recovery from failure. It also demonstrates the capability of the supply chain to succeed after failure (Zhang \& van Luttervelt, 2011). Thus, resilient supply chain must be able to change and reconfigure its structure and resources in space and time to achieve the required functions (Zhang \& Lin, 2010). In fact, measuring the success of the supply chain after a failure is crucial issue that should be addressed to provide managers with a broader view of the ability of the supply chain to respond to the new market changes by including other aspects of resilience.

\section{References}

Andersen, A.-L., Brunoe, T. D., \& Nielsen, K. (2015). Reconfigurable manufacturing on multiple levels: literature review and research directions. In S. Umeda, M. Nakano, H. Mizuyama, N. Hibino, D. Kiritsis, \& G. von Cieminski (Eds.), Advances in production management systems: innovative production management towards sustainable growth (pp. 266-273). Cham: Springer. https://doi. org/10.1007/978-3-319-22756-6_33

Beauville dit Eynaud, A., Klement, N., Gibaru, O., Roucoules, L., \& Durville, L. (2019). Identification of reconfigurability enablers and weighting of reconfigurability characteristics based on a case study. Procedia Manufacturing, 28, 96-101. https://doi.org/10. 1016/j.promfg.2018.12.016

Bensoussia, T., Zidi, S., Hamani, N., Kermad, L., \& Benaissa, M. (2021). A new approach to decision making for supply chain reconfiguration under uncertainty. Systems Science and Control Engineering. (In Press).

Bi, Z. M., Gruver, W. A., \& Zhang, W. J. (2003). Adaptability of reconfigurable robotic systems. In 2003 IEEE International Conference on Robotics and Automation (Cat. No.03CH37422) (Vol. 2, pp. 2317-2322 vol.2). Presented at the 2003 IEEE International Conference on Robotics and Automation (Cat. No.03CH37422). https://doi.org/10.1109/ROBOT.2003.1241939

Bi, Z. M., Lin, Y., \& Zhang, W. J. (2010). The general architecture of adaptive robotic systems for manufacturing applications. Robotics and Computer-Integrated Manufacturing, 26(5), 461-470. https:// doi.org/10.1016/j.rcim.2010.03.002

Bin Ma, Xia, L. X. X., \& Lim, R. (2007). Modeling supply chain's reconfigurability using fuzzy logic. In 2007 IEEE Conference on Emerging Technologies and Factory Automation (EFTA 2007) (pp. 234-241). Presented at the 12th IEEE International Conference on Emerging Technologies and Factory Automation, Patras: IEEE. https://doi.org/10.1109/EFTA.2007.4416774

Biswas, P. (2017). Modeling reconfigurability in supply chains using total interpretive structural modeling. Journal of Advances in Management Research, 14(2), 194-221. https://doi.org/10.1108/ JAMR-09-2016-0071

Biswas, P., Kumar, S., Jain, V., \& Chandra, C. (2019). Measuring supply chain reconfigurability using integrated and deterministic assessment models. Journal of Manufacturing Systems, 52, 172-183. https://doi.org/10.1016/j.jmsy.2019.05.008

Caridi, M., Crippa, L., Perego, A., Sianesi, A., \& Tumino, A. (2010). Do virtuality and complexity affect supply chain visibility? International Journal of Production Economics, 127(2), 372-383. https://doi.org/10.1016/j.ijpe.2009.08.016

Chandra, C., \& Grabis, J. (2016). Supply Chain Configuration: Concepts, Solutions, and Applications (2nd ed.). New York: SpringerVerlag. https://doi.org/10.1007/978-1-4939-3557-4
Chandra, C., \& Kamrani, A. (2004). Mass Customization. Springer. https://doi.org/10.1007/978-1-4419-9015-0

Chaube, A., Benyoucef, L., \& Tiwari, M. K. (2012). An adapted NSGA-2 algorithm based dynamic process plan generation for a reconfigurable manufacturing system. Journal of Intelligent Manufacturing, 23(4), 1141-1155. https://doi.org/10.1007/ s10845-010-0453-9

Chen, S.-J. (Gary), \& Huang, E. (2007). A systematic approach for supply chain improvement using design structure matrix. Journal of Intelligent Manufacturing, 18(2), 285-299. https://doi.org/10. 1007/s10845-007-0022-z

Chinnathai, M. K., Alkan, B., \& Harrison, R. (2017). Convertibility evaluation of automated assembly system designs for high variety production. Procedia CIRP, 60, 74-79. https://doi.org/10.1016/j. procir.2017.01.005

Dahane, M., \& Benyoucef, L. (2016). An adapted NSGA-II algorithm for a reconfigurable manufacturing system (RMS) design under machines reliability constraints. In E.-G. Talbi, F. Yalaoui, \& L. Amodeo (Eds.), Metaheuristics for production systems (Vol. 60, pp. 109-130). Cham: Springer International Publishing. https:// doi.org/10.1007/978-3-319-23350-5_5

Delorme, X., Malyutin, S., \& Dolgui, A. (2016). A multi-objective approach for design of reconfigurable transfer lines. IFAC-PapersOnLine, 49(12), 509-514. https://doi.org/10.1016/j.ifacol.2016. 07.675

Dolgui, A., \& Ivanov, D. (2020). Exploring supply chain structural dynamics: New disruptive technologies and disruption risks. International Journal of Production Economics, 229, 107886. https://doi.org/10.1016/j.ijpe.2020.107886

Dolgui, A., Ivanov, D., \& Sokolov, B. (2018). Ripple effect in the supply chain: An analysis and recent literature. International Journal of Production Research, 56(1-2), 414-430. https://doi. org/10.1080/00207543.2017.1387680

Dolgui, A., Ivanov, D., \& Sokolov, B. (2020). Reconfigurable supply chain: The X-network. International Journal of Production Research, 58(13), 4138-4163. https://doi.org/10.1080/00207 543.2020.1774679

Durowoju, O. A., Chan, H. K., \& Wang, X. (2011). The impact of security and scalability of cloud service on supply chain performance, 12(4), 15.

ElMaraghy, H. A. (2005). Flexible and reconfigurable manufacturing systems paradigms. International Journal of Flexible Manufacturing Systems, 17(4), 261-276. https://doi.org/10.1007/ s10696-006-9028-7

Ezzat, O., Medini, K., Boucher, X., \& Delorme, X. (2020). A clustering approach for modularizing service-oriented systems. Journal of Intelligent Manufacturing. https://doi.org/10.1007/ s10845-020-01668-w

Farid, A. M. (2014). Measures of reconfigurability and its key characteristics in intelligent manufacturing systems. Journal of Intelligent Manufacturing, 28(2), 353-369. https://doi.org/10. 1007/s10845-014-0983-7

Goyal, K. K., \& Jain, P. K. (2015). Design of reconfigurable flow lines using MOPSO and maximum deviation theory. The International Journal of Advanced Manufacturing Technology. https://doi.org/10.1007/s00170-015-7760-4

Goyal, K. K., Jain, P. K., \& Jain, M. (2012). Optimal configuration selection for reconfigurable manufacturing system using NSGA II and TOPSIS. International Journal of Production Research, 50(15), 4175-4191. https://doi.org/10.1080/00207543.2011. 599345

Graman, G. A. (2010). A partial-postponement decision cost model. European Journal of Operational Research, 201(1), 34-44. https://doi.org/10.1016/j.ejor.2009.03.001

Gumasta, K., Kumar Gupta, S., Benyoucef, L., \& Tiwari, M. K. (2011). Developing a reconfigurability index using 
multi-attribute utility theory. International Journal of Production Research, 49(6), 1669-1683. https://doi.org/10.1080/00207 540903555536

Gupta, A., Jain, P. K., \& Kumar, D. (2015). Configuration selection of reconfigurable manufacturing system based on performance. International Journal of Industrial and Systems Engineering, 20(2), 209. https://doi.org/10.1504/IJISE.2015.069543

Hamta, N., Akbarpour Shirazi, M., Behdad, S., \& Fatemi Ghomi, S. M. T. (2018). Modeling and measuring the structural complexity in assembly supply chain networks. Journal of Intelligent Manufacturing, 29(2), 259-275. https://doi.org/10.1007/ s10845-015-1106-9

Ivanov, D. (2020). Viable supply chain model: Integrating agility, resilience and sustainability perspectives-lessons from and thinking beyond the COVID-19 pandemic. Annals of Operations Research. https://doi.org/10.1007/s10479-020-03640-6

Ivanov, D., \& Dolgui, A. (2020). OR-methods for coping with the ripple effect in supply chains during COVID-19 pandemic: Managerial insights and research implications. International Journal of Production Economics. https://doi.org/10.1016/j. ijpe.2020.107921

Ivanov, D., Dolgui, A., Sokolov, B., \& Ivanova, M. (2017). Literature review on disruption recovery in the supply chain. International Journal of Production Research, 55(20), 6158-6174. https://doi. org/10.1080/00207543.2017.1330572

Kelepouris, T., Wong, C. Y., Farid, A. M., Parlikad, A. K., \& McFarlane, D. C. (2006). Towards a reconfigurable supply network model. In intelligent production machines and systems (pp. 481-486). Elsevier. https://doi.org/10.1016/B978-008045157-2/ 50085-7

Koren, Y., Heisel, U., Jovane, F., Moriwaki, T., Pritschow, G., Ulsoy, G., \& Van Brussel, H. (1999). Reconfigurable manufacturing systems. CIRP Annals, 48(2), 527-540. https://doi.org/10.1016/ S0007-8506(07)63232-6

Koren, Y., \& Shpitalni, M. (2010). Design of reconfigurable manufacturing systems. Journal of Manufacturing Systems, 29(4), 130-141. https://doi.org/10.1016/j.jmsy.2011.01.001

Maganha, I., Silva, C., Ferreira, L. M. D. F., Thurer, M., Frazzon, E. M., \& Silvestri, M. (2019). Proposal of a reconfigurability index using analytic network process. In 2019 IEEE International Conference on Industrial Engineering and Engineering Management (IEEM) (pp. 1310-1313). Presented at the 2019 IEEE International Conference on Industrial Engineering and Engineering Management (IEEM), Macao, Macao: IEEE. https://doi.org/10. 1109/IEEM44572.2019.8978532

Maganha, Isabela, Silva, C., \& Ferreira, L. M. D. F. (2018). Understanding reconfigurability of manufacturing systems-An empirical analysis. Journal of Manufacturing Systems, 11.

Maganha, I., Silva, C., \& Ferreira, L. M. D. F. (2019b). An analysis of reconfigurability in different business production strategies. IFAC-PapersOnLine, 52(13), 1028-1033. https://doi.org/10. 1016/j.ifacol.2019.11.330

Maler-Speredelozzi, V., Koren, Y., \& Hu, S. J. (2003). Convertibility measures for manufacturing systems. CIRP Annals, 52(1), 367370. https://doi.org/10.1016/S0007-8506(07)60603-9

Mehrabi, M. G., Ulsoy, A. G., \& Koren, Y. (2000). Reconfigurable manufacturing systems: Key to future manufacturing I SpringerLink. Journal of Intelligent Manufacturing, 11, 403-419.

Mittal, K. K., \& Jain, P. K. (2014). An overview of performance measures in reconfigurable manufacturing system. Procedia Engineering, 69, 1125-1129. https://doi.org/10.1016/j.proeng.2014.03.100

Napoleone, A., Pozzetti, A., \& Macchi, M. (2018a). A framework to manage reconfigurability in manufacturing. International Journal of Production Research, 56(11), 3815-3837. https://doi.org/10. 1080/00207543.2018.1437286
Napoleone, A., Pozzetti, A., \& Macchi, M. (2018b). Core characteristics of reconfigurability and their influencing elements. IFACPapersOnLine, 51(11), 116-121. https://doi.org/10.1016/j.ifacol. 2018.08.244

Palmer, C., Urwin, E. N., Niknejad, A., Petrovic, D., Popplewell, K., \& Young, R. I. M. (2018). An ontology supported risk assessment approach for the intelligent configuration of supply networks. Journal of Intelligent Manufacturing, 29(5), 1005-1030. https:// doi.org/10.1007/s10845-016-1252-8

Prasad, D., \& Jayswal, S. C. (2019). Assessment of a reconfigurable manufacturing system. Benchmarking: An International Journal, BIJ-06-2018-0147. https://doi.org/10.1108/BIJ-06-2018-0147

Raj, R., Wang, J. W., Nayak, A., Tiwari, M. K., Han, B., Liu, C. L., \& Zhang, W. J. (2015). Measuring the resilience of supply chain systems using a survival model. IEEE Systems Journal, 9(2), 377-381. Presented at the IEEE Systems Journal. https://doi.org/ 10.1109/JSYST.2014.2339552

Rösiö, C., Aslam, T., Srikanth, K. B., \& Shetty, S. (2019). Towards an assessment criterion of reconfigurable manufacturing systems within the automotive industry. Procedia Manufacturing, 28, 76-82. https://doi.org/10.1016/j.promfg.2018.12.013

Shahzad, K. M., \& Hadj-Hamou, K. (2013). Integrated supply chain and product family architecture under highly customized demand. Journal of Intelligent Manufacturing, 24(5), 1005-1018. https:// doi.org/10.1007/s10845-012-0630-0

Sheffi, Y., \& Rice, J. B., Jr. (2005). A supply chain view of the resilient enterprise. MIT Sloan Management Review, 47(1), 12.

Velasquez, M., \& Hester, P. T. (2013). An analysis of multi-criteria decision making methods, 10(2), 12.

Wang, F., Qian, Z., Yan, Z., Yuan, C., \& Zhang, W. (2020). A novel resilient robot: kinematic analysis and experimentation. IEEE Access, 8, 2885-2892. Presented at the IEEE Access. https://doi. org/10.1109/ACCESS.2019.2962058

Wang, G. X., Huang, S. H., Yan, Y., \& Du, J. J. (2016a). Reconfiguration schemes evaluation based on preference ranking of key characteristics of reconfigurable manufacturing systems. The International Journal of Advanced Manufacturing Technology, 89(5), 2231-2249. https://doi.org/10.1007/s00170-016-9243-7

Wang, J., Dou, R., Muddada, R. R., \& Zhang, W. (2018). Management of a holistic supply chain network for proactive resilience: Theory and case study. Computers and Industrial Engineering, 125, 668-677. https://doi.org/10.1016/j.cie.2017.12.021

Wang, J., Muddada, R. R., Wang, H., Ding, J., Lin, Y., Liu, C., \& Zhang, W. (2016). Toward a resilient holistic supply chain network system: Concept, review and future direction. IEEE Systems Journal, 10(2), 410-421. Presented at the IEEE Systems Journal. https://doi.org/10.1109/JSYST.2014.2363161

Wang, J. W., Gao, F., \& Ip, W. H. (2010). Measurement of resilience and its application to enterprise information systems. Enterprise Information Systems, 4(2), 215-223. https://doi.org/10.1080/ 17517571003754561

Wei, H., \& Wang, E. T. G. (2007). Creating strategic value from supply chain visibility- the dynamic capabilities view. In 2007 40th Annual Hawaii International Conference on System Sciences (HICSS'07) (pp. 7-7). Presented at the 2007 40th Annual Hawaii International Conference on System Sciences (HICSS'07). https:// doi.org/10.1109/HICSS.2007.157

Wiendahl, H. P., \& Heger, C. L. (2004). Justifying changeability. A methodical approach to achieving cost effectiveness. Journal for Manufacturing Science and Production, 6(1-2), 33-40. https:// doi.org/10.1515/IJMSP.2004.6.1-2.33

Zebardast, M., Malpezi, S., \& Taisch, M. (2013). Mass customization in supply chain level: Development of a conceptual framework to manage and assess performance. In V. Prabhu, M. Taisch, \& D. Kiritsis (Eds.), Advances in production management systems. 
sustainable production and service supply chains (Vol. 415, pp. 81-90). Springer. https://doi.org/10.1007/978-3-642-41263-9_11

Zhang, W. J., \& Lin, Y. (2010). On the principle of design of resilient systems - application to enterprise information systems. Enterprise Information Systems, 4(2), 99-110. https://doi.org/10.1080/ 17517571003763380

Zhang, W. J., Lin, Y., \& Sinha, N. (2005). On the function-behaviorstructure model for design. In Proceedings of the Canadian Engineering Education Association (CEEA). https://doi.org/10.24908/ pceea.v0i0.3884

Zhang, W. J., \& van Luttervelt, C. A. (2011). Toward a resilient manufacturing system. CIRP Annals, 60(1), 469-472. https://doi.org/ 10.1016/j.cirp.2011.03.041

Zhang, W. J., \& Wang, J. W. (2016). Design theory and methodology for enterprise systems. Enterprise Information Systems, 10(3), 245-248. https://doi.org/10.1080/17517575.2015.1080860
Zidi, H., Hamani, N., Laajili, C., \& Benaissa, M. (2021). A reconfiguration approach for a supply chain tracking platform. International Journal of Shipping and Transport Logistics: Inderscience Publishers.

Zidi, S., Hamani, N., \& Kermad, L. (2019). Proposition d'une approche de reconfiguration des processus métiers de la chaîne logistique. Génie industriel et productique, 2(1). https://doi.org/10.21494/ ISTE.OP.2019.0374

Publisher's Note Springer Nature remains neutral with regard to jurisdictional claims in published maps and institutional affiliations. 